\title{
PROGRESS IN NUCLEAR FUEL TECHNOLOGY IN KOREA
}

\author{
KUN WOO SONG ${ }^{\prime}$, KYEONG LAK JEON ${ }^{2}$, YOUNG KI JANG ${ }^{2}$, JOO HWAN PARK ${ }^{1}$ and YANG-HYUN KOO \\ ${ }^{1}$ Korea Atomic Energy Research Institute \\ 1045 Daedeokdaero, Yuseong-Gu, Daejeon 305-353, Korea \\ ${ }^{2}$ Korea Nuclear Fuel \\ 1047 Daedeokdaero, Yuseong-Gu, Daejeon 305-353, Korea \\ "Corresponding author. E-mail : kwsong@kaeri.re,kr
}

Invited February 11, 2009

Received March 31, 2009

During the last four decades, 16 Pressurized Water Reactors (PWR) and 4 Pressurized Heavy Water Reactors (PHWR) have been constructed and operated in Korea, and nuclear fuel technology has been developed to a self-reliant state. At first, the PWR fuel design and manufacturing technology was acquired through international cooperation with a foreign partner. Then, the PWR fuel R\&D by Korea Atomic Energy Research Institute (KAERI) has improved fuel technology to a self-reliant state in terms of fuel elements, which includes a new cladding material, a large-grained $\mathrm{UO}_{2}$ pellet, a high performance spacer grid, a fuel rod performance code, and fuel assembly test facility. The MOX fuel performance analysis code was developed and validated using the in-reactor test data. MOX fuel test rods were fabricated and their irradiation test was completed by an international program. At the same time, the PWR fuel development by Korea Nuclear Fuel (KNF) has produced new fuel assemblies such as PLUS7 and ACE7. During this process, the design and test technology of fuel assemblies was developed to a self-reliant state. The PHWR fuel manufacturing technology was developed and manufacturing facility was set up by KAERI, independently from the foreign technology. Then, the advanced PHWR fuel, CANFLEX(CANDU Flexible Fuelling), was developed, and an irradiation test was completed in a PHWR. The development of the CANFLEX fuel included a new design of fuel rods and bundles.. The nuclear fuel technology in Korea has been steadily developed in many national R\&D programs, and this advanced fuel technology is expected to contribute to a worldwide nuclear renaissance that can create solutions to global warming.

KEYWORDS : High Burnup Fuel, Cladding, UO2 Pellet, Mixing Vane, Spacer Grid, Fuel Assembly Test, MOX Fuel, CANDU Fuel, CANFLEX Fuel, PLUS7 Fuel, ACE7 Fuel.

\section{INTRODUCTION}

Since the first PWR plant, Kori \#1, was constructed in 1978 , Korea has expanded nuclear power generation. Now 16 PWRs and 4 PHWRs are operating with 8 PWRs to be built by 2017 , and 10 more PWRs planned to be constructed by 2030 . During the past four decades, nuclear fuel technology has gradually been improving in Korea. The technology evolution can be characterized by 3 phases: total dependence on foreign technology, semi self-reliance of technology utilizing foreign technology, and self-reliance of technology.

Regarding the PWR fuel technology, basic research was carried out for the first phase. The semi self-reliance phase started in 1986 when Korea Atomic Energy Research Institute (KAERI) took part in a "joint design" of PWR fuel with Siemens-KWU. Through this process, Korea acquired total fuel design technology including design codes, experimental database, and design methodology. Korea Nuclear Fuel (KNF) established the
PWR fuel manufacturing technology, based on SiemensKWU technology, and then manufactured and provided PWR fuels for all of the PWRs in Korea.

KAERI started a R\&D program for developing selfreliant advanced fuel technology in 1997. Many promising R\&D results were produced, including a high corrosionresistant cladding, a large-grained $\mathrm{UO}_{2}$ pellet, a high performance spacer grid, and full-size assembly test facilities for mechanical and thermal-hydraulic purposes. KNF carried out several R\&D programs for the purpose of improving reliability and economy of commercial fuels. The so-called "PLUS7" and "ACE7" fuels were developed and provided for Optimized Power Reactor (OPR) 1000 reactor and Westinghouse-type reactors, respectively.

In parallel with the evolution of PWR fuel technology, the PHWR fuel technology improved. KAERI developed the manufacturing technology of CANDU fuel without relying on foreign technology in 1987 and provided it for the Wolsong \#1. KAERI also succeeded in developing CANFLEX fuel in cooperation with AECL in order to 
improve safety and economy of a PHWR.

This paper will mainly describe the technical achievements in PWR and PHWR fuels for the selfreliance phase. KAERI and KNF have played major roles in developing advanced fuel technology. So the PWR fuel technology is divided into two parts: the first part for KAERI' R\&D and the second part for KNF's development. The part of PHWR fuel technology consists mainly of KAERI's R\&D results.

\section{PWR FUEL R\&D IN KAERI}

From the mid 1980s to the mid 1990s, Korea Atomic Energy Research Institute (KAERI) developed fuel design technology for all PWR fuel types utilizing the SimensKWU technology. The design technology was transferred to Korea Nuclear Fuel, the sole fuel vendor in Korea. Then, KAERI launched a R\&D program for developing self-reliant advanced fuel technology that would enhance fuel reliability and economy.

The advanced PWR fuel focused on a high burn-up fuel since this could reduce the fuel cycle cost and the amount of spent fuel. High burn-up fuel has been studied world-wide for the purpose of solving or relaxing the anticipated concerns of high burn-up, such as cladding corrosion, fission gas release, and so on. The elementary technology that KAERI developed addressed each high burn-up issue. So the R\&D topics of KAERI included essentially the development of high corrosion-resistant cladding alloys, large grain $\mathrm{UO}_{2}$ pellets, fuel performance analysis code, and high performance grids.

Table 1. Summary of PWR Fuel R\&D in KAERI

\begin{tabular}{l|l|l}
\hline & \multicolumn{1}{|c|}{ Activities } & Achievements \\
\hline Cladding & $\begin{array}{l}\text { Alloy design, cladding } \\
\text { fabrication, lab \& in-rector test }\end{array}$ & HANA claddings \\
\hline Fuel Pellet & $\begin{array}{l}\text { Fabrication method, in-reactor } \\
\text { test }\end{array}$ & $\begin{array}{l}\text { Large-grain UO } \\
\text { pellet }\end{array}$ \\
\hline $\begin{array}{l}\text { Performance } \\
\text { Analysis }\end{array}$ & $\begin{array}{l}\text { Model \& code development, } \\
\text { PIE test }\end{array}$ & INFRA code \\
\hline Spacer Grid & $\begin{array}{l}\text { Shape design, grid fabrication, } \\
\text { mechanical \& thermal } \\
\text { hydraulic test }\end{array}$ & $\begin{array}{l}\text { Theta-shaped } \\
\text { spring \& hybrid } \\
\text { mixing vane }\end{array}$ \\
\hline Test facility & $\begin{array}{l}\text { Construction of full size FA } \\
\text { mechanical \& thermal-hydraulic } \\
\text { test, Compatibility test }\end{array}$ & $\begin{array}{l}\text { FaMect, HTL, } \\
\text { PLUTO }\end{array}$ \\
\hline
\end{tabular}

At the same time, fundamental studies were carried out on a fuel performance database and fuel assembly tests. Significant progress was made during the last 10 years (1997-2006)[1]. The achievements of each area, as well as a. summary of the R\&D areas are shown in Table 1.

\subsection{Cladding Technology}

Waterside corrosion of fuel claddings has been considered as one of the main limitations to a burn-up extension of nuclear fuel and thus has been a key issue in improving the economical efficiency of light water reactors. A series of $\mathrm{Nb}$-containing $\mathrm{Zr}$ alloys named HANA (High performance Alloy for Nuclear Application) has been developed to improve the corrosion resistance of the fuel claddings [2-6]. A total of 6 kinds of HANA claddings have been fabricated, with each cladding being subjected to more than 10 different annealing conditions in order to optimize the heat treatment condition for improved properties. The fabricated HANA claddings were subjected to a variety of out-of-pile tests including corrosion, creep and LOCA tests, as well as in-pile tests in the Halden research reactor.

Figure 1 shows the corrosion behavior of HANA-4 (Zr-1.5Nb-0.4Sn-0.2Fe-0.1Cr), HANA-6 (Zr-1.1Nb$0.05 \mathrm{Cu}$ ), and Zircaloy-4 (Zr-1.3Sn-0.2Fe-0.1Cr) in the PWR-simulating loop conditions. HANA-4 and HANA6 alloys showed a lower corrosion rate compared to Zircaloy-4, regardless of the final annealing temperatures. HANA- 6 exhibited a better corrosion resistance than HANA-4 when the final annealing conditions were identical. The microstructure observation revealed that the precipitate size in the HANA claddings was finer than that of Zricaoly-4, which was considered to be one of the main reasons for the better corrosion resistance of

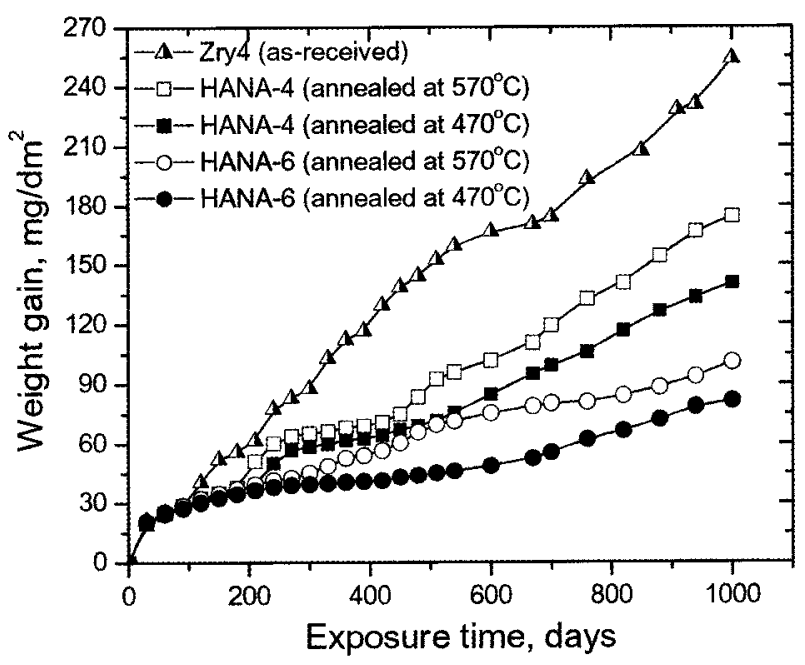

Fig. 1. Corrosion Behavior of HANA Claddings in a PWRSimulating Loop Containing 2.2ppm Li and 650ppm B [2] 


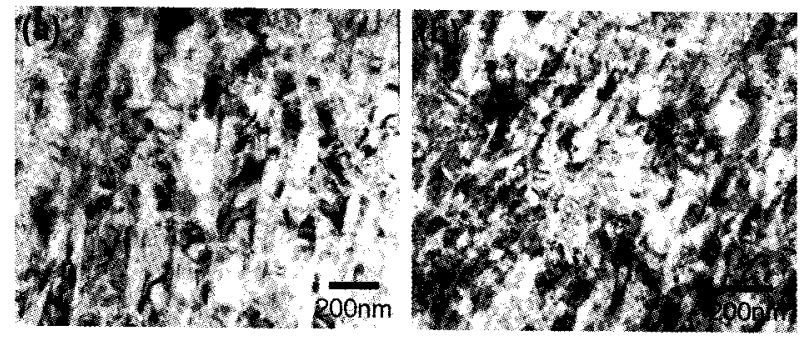

Fig. 2. Microstructure of the Oxide/Metal Interface Region in the Oxide Formed on HANA-6 Annealed at (a) $470^{\circ} \mathrm{C}$ and (b) $570^{\circ} \mathrm{C}$ after 1000 Days in PWR-simulating Loop [3]

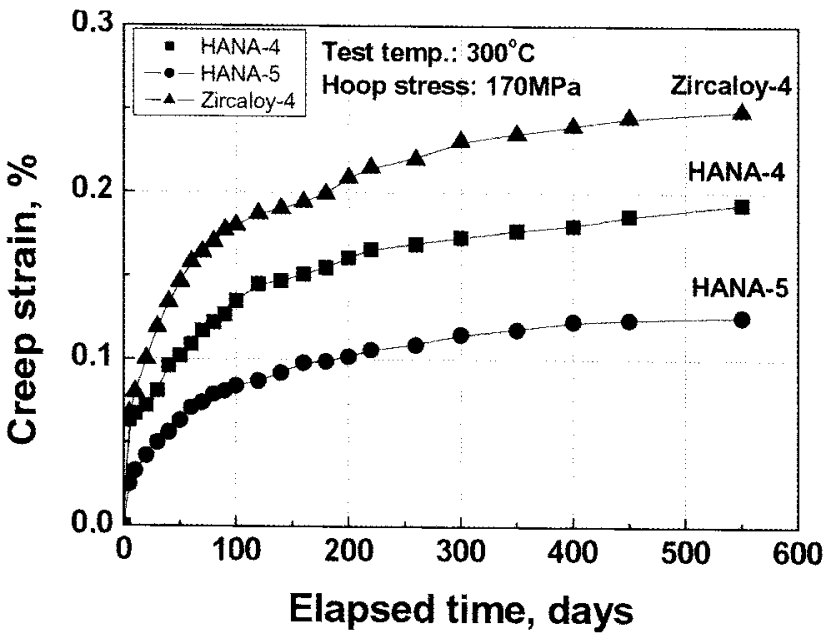

Fig. 3. Thermal Creep Properties of the HANA Claddings

the HANA claddings. The optimum corrosion performance of the $\mathrm{Nb}$-containing $\mathrm{Zr}$ alloys was achieved when the fine second phase particles were uniformly precipitated in the matrix [7-8].

It was also found that the corrosion resistance of the HANA claddings was highly dependent on the heat treatment condition in the manufacturing process and that the final annealing at a lower temperature is more desirable for the improvement of the corrosion resistance. Figure 2 shows the oxide microstructure in the oxide/metal interface region of HANA- 6 annealed at $470^{\circ} \mathrm{C}$ and $570^{\circ} \mathrm{C}$. The size of the columnar grains ranged from 30 to $60 \mathrm{~nm}$ in width and from 300 to $500 \mathrm{~nm}$ in length in HANA-6 annealed at $470^{\circ} \mathrm{C}$. For the higher final annealing temperature $\left(570^{\circ} \mathrm{C}\right)$, the columnar grain size decreased slightly in both width and length. As mentioned earlier, the corrosion rate of HANA-6 increased with an increase of the final annealing temperature, which correlates well with the reduction in size of the columnar grains in the oxide/metal interface region. Columnar grains are more desirable to slow down the diffusion rate of oxygen ions

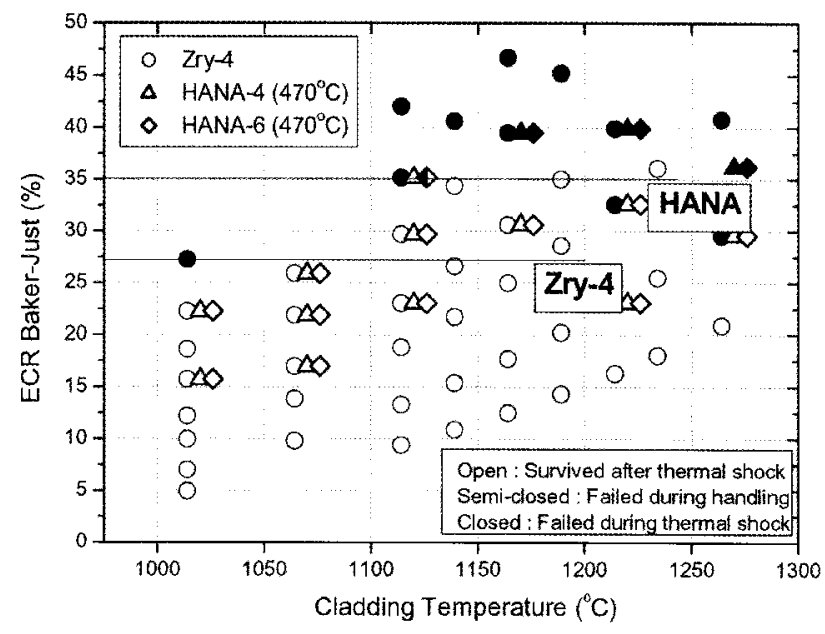

Fig. 4. Failure Map of the HANA Claddings with the Oxidation Temperature and ECR Value [9]

when compared to equiaxed grains since the grain boundaries provide the main diffusion path for oxygen ions. Such a beneficial effect would be enhanced if the size of the columnar grains increased. Therefore, the lower corrosion rate observed in the alloys annealed at $470^{\circ} \mathrm{C}$ is probably attributed to the larger columnar oxide grains.

A thermal creep test was performed to evaluate the out-of-pile creep properties of the HANA claddings. An internal pressurization test was carried out, which was designed to create a hoop stress at a certain test temperature by an injection of Ar gas. Figure 3 shows the diametral strain of the HANA claddings that were heat treated at $510^{\circ} \mathrm{C}$. Each cladding shows a steady state secondary creep behavior after 75 days, where the HANA claddings showed a lower creep rate than Zircaloy-4. HANA-5 (Zr$0.4 \mathrm{Nb}-0.8 \mathrm{Sn}-0.35 \mathrm{Fe}-0.15 \mathrm{Cr}-0.1 \mathrm{Cu})$ exhibited a better creep resistance than HANA-4. From the results of the thermal creep test of the HANA claddings, it was found that an optimization of the final heat treatment temperature, as well as the alloying elements, is crucial for an improvement of the creep resistance.

A thermal quench test was performed, in which the specimen was oxidized in a flowing steam at a desired temperature up to $1200^{\circ} \mathrm{C}$ and then quenched in water. The threshold ECR (Equivalent Cladding Reacted) of each cladding was evaluated. Figure 4 shows the failure map of the thermally quenched Zircaloy-4 and the HANA claddings after a subsequent high temperature oxidation [9]. The open symbol represents a specimen that remained intact after water quenching. A closed symbol represents a specimen that failed. The threshold ECR value of the HANA claddings was higher than the conventional value of $17 \%$ for Zircaloy- 4 , which was mainly due to the fact that the $\mathrm{Nb}$ decreased the oxidation rate, as well as the hydrogen pickup rate. 


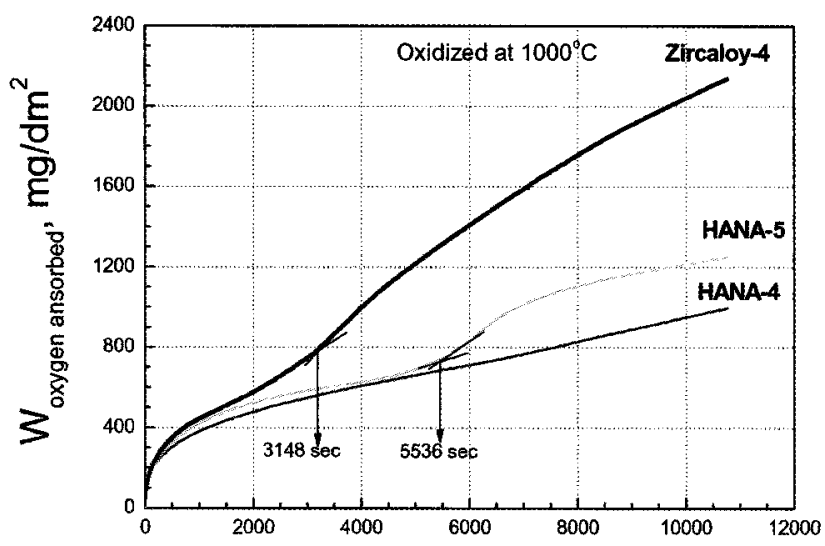

Fig. 5. High Temperature Oxidation Behaviors of HANA Claddings at $1000^{\circ} \mathrm{C}[10]$

\section{Burn-up, GWD/MTU}

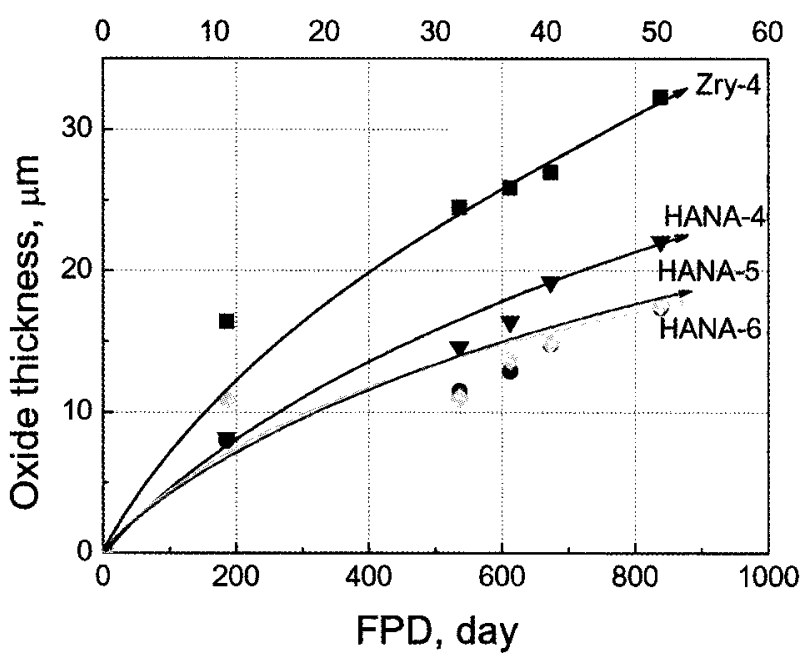

Fig. 6. In-pile Corrosion Properties of HANA Claddings

The high temperature oxidation behavior of HANA claddings was examined by using the steam oxidation experiments performed at $1000^{\circ} \mathrm{C}$. The long-term oxidation behaviors of the tube-type specimens are shown in Figure 5. The weight gain of the HANA-4 increased slowly as the exposure time was extended to $10800 \mathrm{~s}$. No breakaway oxidation behavior was detected up to the exposure time at $1000^{\circ} \mathrm{C}$ in HANA-4. However, the breakaway oxidation behaviors at the same temperature were observed in Ziracloy-4 and HANA-5 alloys. The breakaway oxidation of the HANA-5 occurred after an exposure for about 5500s whereas Zircaloy-4 showed the breakaway after 3100 s. It is possible to suppose that the breakaway oxidation kinetics was influenced by the chemical composition of the $\mathrm{Zr}$ alloys.
The in-pile tests of the HANA claddings have been performed in the Halden research reactor since 2003. The test rods manufactured by HANA claddings were irradiated for about 838 full power days corresponding to about 50 MWD/kgU. The water chemistry, fluence, and thermal hydraulic conditions were similar to those of commercial PWRs during the irradiation test. The oxide thicknesses of the test rods ranged from 17 to $32 \mu \mathrm{m}$ depending on the alloy composition and axial position. The change of the average oxide thickness for the highest heat flux region of each segment is also plotted in Figure 6 for all the test rods. HANA claddings showed a better corrosion resistance than the reference cladding. The corrosion resistance of the HANA claddings was improved by $40 \sim 50 \%$ when compared to the reference cladding on the basis of the oxide thickness measurements. It was confirmed that all the HANA claddings had an excellent corrosion resistance in the in-reactor conditions, as well as the outof-pile conditions.

\section{$2.2 \mathrm{UO}_{2}$ Pellet Technology}

Uranium dioxide has been used as light water reactor fuel pellet materials and fuel pellets have been manufactured by using a conventional powder metallurgical processing method [11]; $\mathrm{UO}_{2}$ powder was pressed into green pellets and then sintered at $1700-1780^{\circ} \mathrm{C}$ in a hydrogen-containing gas. The $\mathrm{UO}_{2}$ pellet properties - density, pore structure, and grain size - greatly influenced the in-reactor performance of the $\mathrm{UO}_{2}$ pellet. Specifically, the amount of fission gas released during the irradiation decreased as the grain size of the $\mathrm{UO}_{2}$ pellets increased [12], and thus large-grain $\mathrm{UO}_{2}$ pellets have been supposed to be beneficial for the high burnup, since the fission gas release was one of the most important requirements for high burn-up fuel.

A lot of fabrication methods for large-grain $\mathrm{UO}_{2}$ pellets were investigated and developed. The most prevailing method was simply to add the sintering agents such as niobia [13,14], titania [15], chromia [16], and magnesia [17]. It is also known that $\mathrm{UO}_{2}$ powder with a high sintering activity can increase the grain size of $\mathrm{UO}_{2}$ pellets without sintering agents [18]. It has also been reported that the addition of $\mathrm{UO}_{2}$ seeds to $\mathrm{UO}_{2}$ powder enhances the grain growth [19].

KAERI reported that a large-grain pellet can be fabricated by using a specially heat-treated uranium oxide seed [20]. Figure 7 shows a schematic picture of the developed $\mathrm{UO}_{2}$ pellet fabrication process. Developed technology has a good adaptability to the conventional fabrication process because it involves simply adding heat-treated uranium oxide seeds to $\mathrm{UO}_{2}$ powder at an amount of less than $6 \mathrm{wt} \%$.

Recycled pellet and powder scrap was used to prepare the heat-treated uranium oxide seeds, such as $\mathrm{U}_{3} \mathrm{O}_{8}$ seeds, $\mathrm{UO}_{2}$ seeds or activated $\mathrm{U}_{3} \mathrm{O}_{8}$. Scanning electron microscope photographs of these various $\mathrm{U}_{3} \mathrm{O}_{8}$ and $\mathrm{UO}_{2}$ powders are presented in Figure 8. The conventionally recycled $\mathrm{U}_{3} \mathrm{O}_{8}$ 


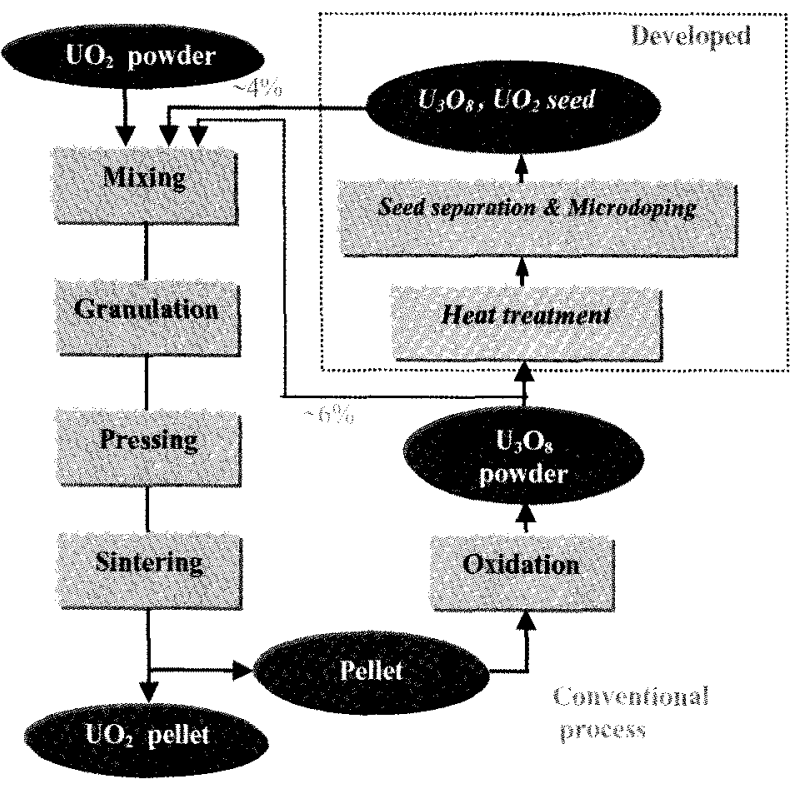

Fig. 7. Schema of $\mathrm{UO}_{2}$ Pellet Fabrication Process

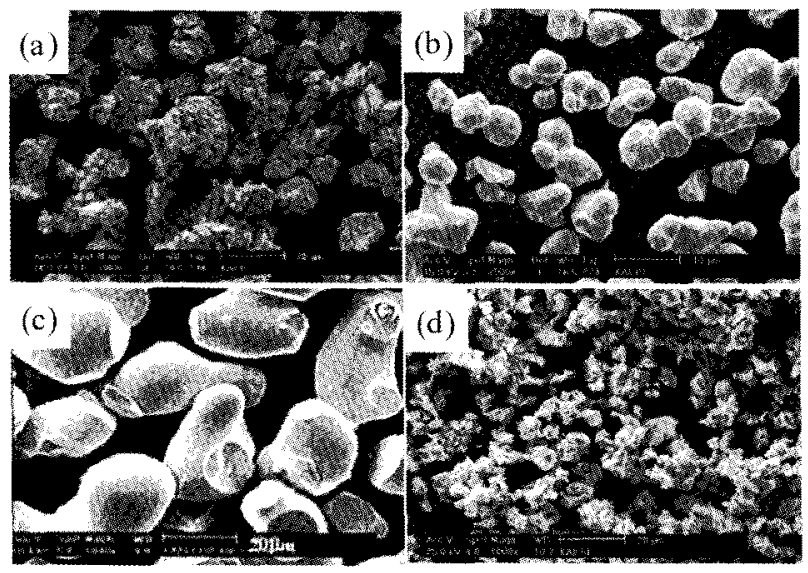

Fig. 8. Typical Shape of (a) Conventional $\mathrm{U}_{3} \mathrm{O}_{8}$, (b) $\mathrm{U}_{3} \mathrm{O}_{8}$ Seed, (c) $\mathrm{UO}_{2}$ Seed and (d) Activated $\mathrm{U}_{3} \mathrm{O}_{8}$

powder is shown in Figure 8(a), and various heat-treated uranium oxide seeds are shown in Figures 8(b)-2(d). When the recycled $\mathrm{U}_{3} \mathrm{O}_{8}$ powder was heat-treated at $1200-1500{ }^{\circ} \mathrm{C}$ for various amount of time in a controlled atmosphere, the size of crystals constituting a $\mathrm{U}_{3} \mathrm{O}_{8}$ particle increased with the temperature. The seeds shown in Figure $8(\mathrm{~b})$ and Figure 8(c) were made by a mechanical dividing process after heat-treatment. The divided seeds had a polyhedron shape and were usually comprised of one grain. In the sintering process of the powder compact containing seeds, a large seed could enhance the grain growth by easily absorbing the surrounding small particles.

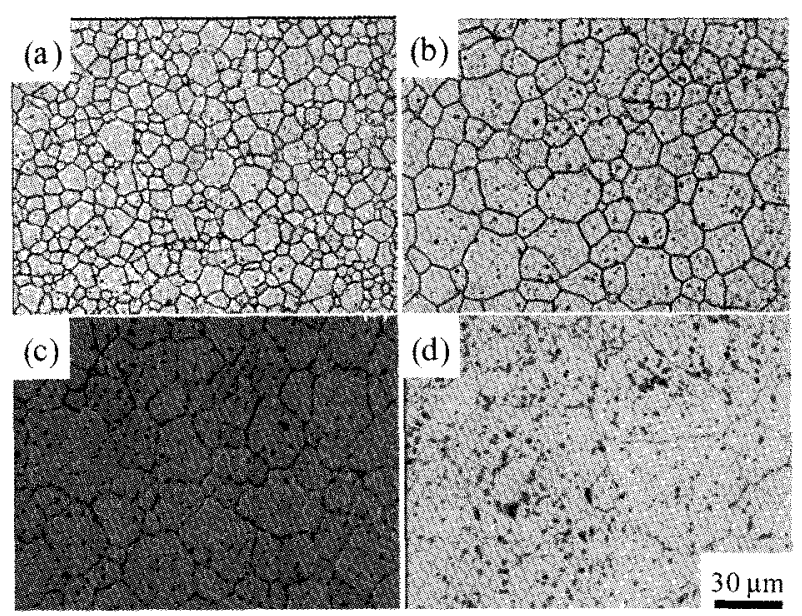

Fig. 9. Microstructures of (a) Conventional, (b) $\mathrm{U}_{3} \mathrm{O}_{8}$ Seeded, (c) Al-microdoped and (d) Al-microdoped seed Added $\mathrm{UO}_{2}$ Pellet

Figure $8(\mathrm{~d})$ represents the activated $\mathrm{U}_{3} \mathrm{O}_{8}$ made by a low temperature oxidation of the scrap pellet or a further oxidation of the divided seeds. The size of an activated $\mathrm{U}_{3} \mathrm{O}_{8}$ was much smaller than that of the conventionally recycled $\mathrm{U}_{3} \mathrm{O}_{8}$. It also had almost two times larger specific area than the conventionally recycled $\mathrm{U}_{3} \mathrm{O}_{8}$. Thus, it can be used as a seed without a drop in density.

The uranium oxide seeds such as $\mathrm{U}_{3} \mathrm{O}_{8}$ seeds, $\mathrm{UO}_{2}$ seeds, and activated $\mathrm{U}_{3} \mathrm{O}_{8}$, successfully acted as a graingrowth promoter. The microstructures of a developed large-grain $\mathrm{UO}_{2}$ pellet are shown in Figure 9 and was compared to that of the conventional $\mathrm{UO}_{2}$ pellet. The grain size of the seeded or micro-doped pellets increased from $8 \mu \mathrm{m}$ to $14 \mu \mathrm{m}$. The content of the seed was usually less than $5 \%$. Aluminum was also used as a dopant, and the doping level was controlled to below $100 \mathrm{ppm}$. A $25 \mu \mathrm{m}$ grain-sized pellet was also developed by combining seeds with micro-doping.

An innovative fuel pellet, $\mathrm{UO}_{2}$-metal cermet fuel pellet, was developed [21]. The purpose was to improve the thermal conductivity of a $\mathrm{UO}_{2}$ pellet by adding a small amount of metal phases such as W, Mo, or Cr. Based on the theory of the phase equilibria among metals, metal oxides, and $\mathrm{UO}_{2}$, a novel fabrication process was developed, in which continuous metal-channel-containing $\mathrm{UO}_{2}$ pellets were produced from a metal-particle-dispersed $\mathrm{UO}_{2}$ pellet through specific annealing and reducing steps. This technique created a metal-channel-containing ceramic composite (even with a small amount of the metal phase of below 10 vol $\%$ ), in contrast to the conventional cermet fuel which requires about 50 vol $\%$ of metal to make a continuous metal channel.

Figures $10(\mathrm{a})$ and $10(\mathrm{~b})$ show a topographical and thermal conductivity contrast image of the polished surface of the developed $\mathrm{UO}_{2}-\mathrm{W}$ cermet sample respectively. 


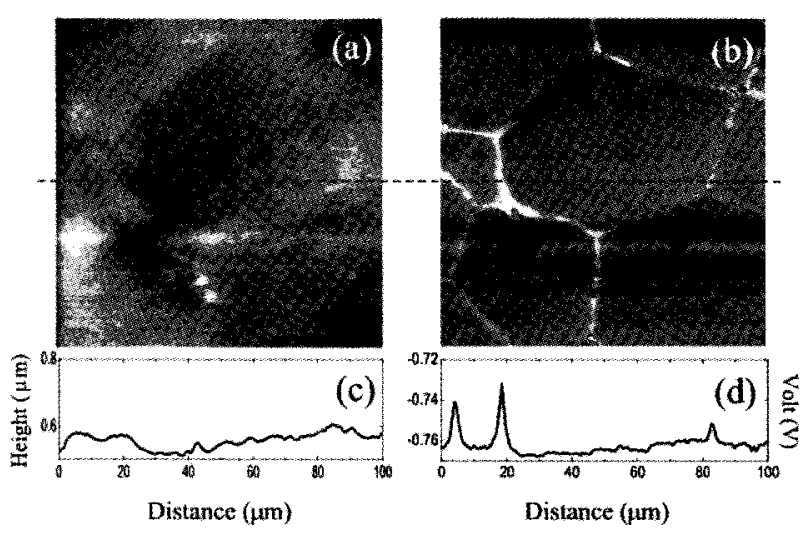

Fig. 10. Topographical and Scanning Thermal Microscope Image of the $\mathrm{W}$ Channel Containing $\mathrm{UO}_{2}$ Pellet.

(a) Topographical Image, (b) SThM Image, (c) Surface Height Variation across the Line Indicated in (a), and (d) Thermal Conductivity Distribution Across the Line Indicated in (b)

Figures $10(\mathrm{c})$ and $10(\mathrm{~d})$ show the profiles of the height and the thermal conductivity along the line indicated in Figures. 10(a) and 10(b), respectively. It can be observed that the height of the surface does not change considerably along the line. But, the thermal conductivity sharply increased at the grain boundary. This fact clearly indicates that the highly thermal conductive phase was continuously formed along the grain boundary and the thermal conductivity of this pellet was increased by this grain boundary phase.

\subsection{High Burnup Fuel Performance and Safety}

$\mathrm{A} \mathrm{UO}_{2}$ fuel rod performance analysis code, INFRA (INtegrated Fuel Rod Analysis) was developed for predicting the fuel rod behavior at high burnup [22]. Various new models which can predict a high burnup effect up to a $70 \mathrm{MWd} / \mathrm{kgU}$ were also developed. These models covered 1) rim structure formation, 2) irradiated fuel thermal conductivity, 3) mechanistic fission gas release, and 4) PCMI by FEM.

The INFRA code was verified using various fuel performance database such as IFPE, HRP and domestic high burnup fuel data. The FUMEX-II program for code verification revealed that the INFRA code prediction shows good agreement with measured data (Figure 11 and Figure 12) [23].

Within the irradiated $\mathrm{UO}_{2}$ fuel, the fission gas remained in two regions: the grain matrix and the boundary. In a normal operating condition, most of the fission gases that remained in the fuel accumulated and stabilized in intra or inter-granular gas bubbles, and some of them (about $5 \sim 10 \%$ ) were released to the rod free volume. In an accident condition such as RIA, these stabilized gas bubbles acted as an additional fission gas release inventory, and the fission gas release mechanisms and release times

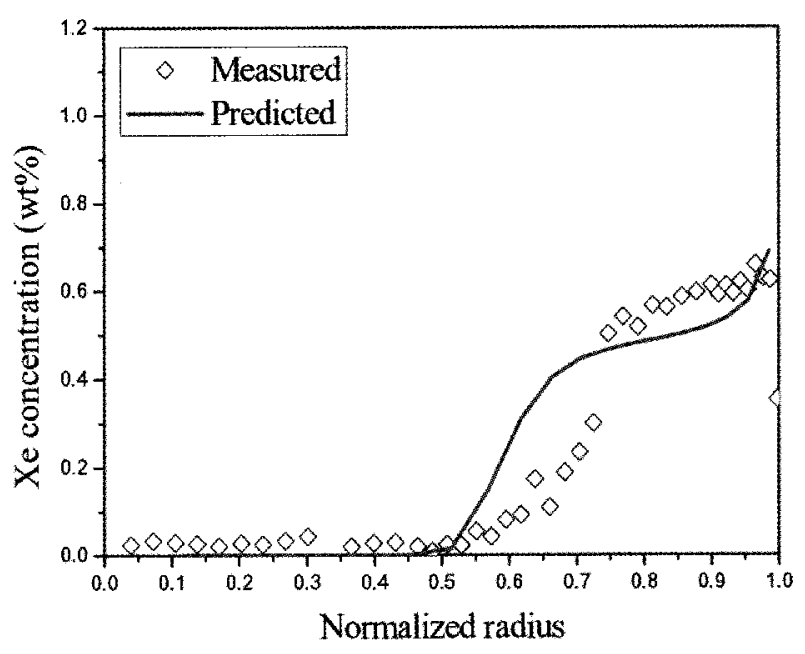

Fig. 11. Predicted Radial Xe Profile

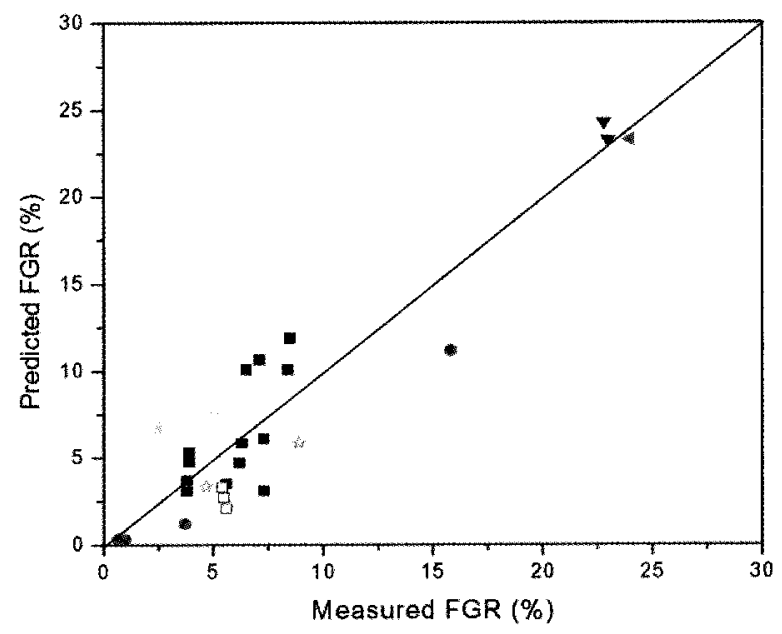

Fig. 12. Fission Gas Release Measured vs. Predicted

were different, depending on their locations (intragranular or inter-granular). The fission gas inventory were distinguished by the controlled technique [24].

To investigate the behavior of fission gases in a high burnup $\mathrm{UO}_{2}$ fuel during a temperature transient, a PIA (Post Irradiation Annealing) apparatus was developed and installed at PIEF(Post Irradiation Examination Facility) in KAERI [25]. Figure 13 shows the $\mathrm{Kr}-85$ release behavior in an oxidizing gas. The inter-granular fission gas inventory was almost all released within $200 \mathrm{~min}$ at $500^{\circ} \mathrm{C}$ After two hours of a holding time at $1400^{\circ} \mathrm{C}$, the $\mathrm{Kr}-85$ release was saturated and no additional fission gas release occurred. The re-heating up to $1400^{\circ} \mathrm{C}$ did not produce an additional fission gas release. After assuming all the $\mathrm{Kr}-85$ was released, the inter-granular fission gas 


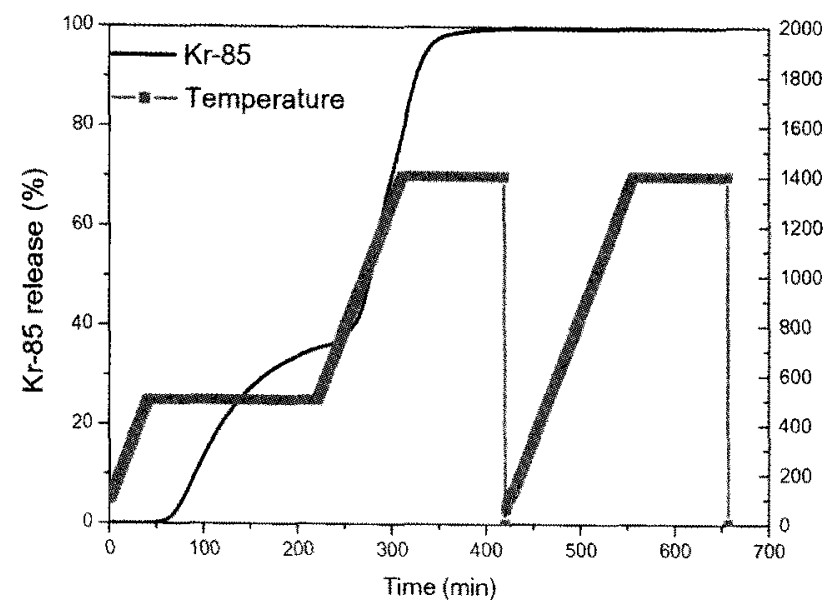

Fig. 13. Kr-85 Release Behavior in an Oxidizing Gas

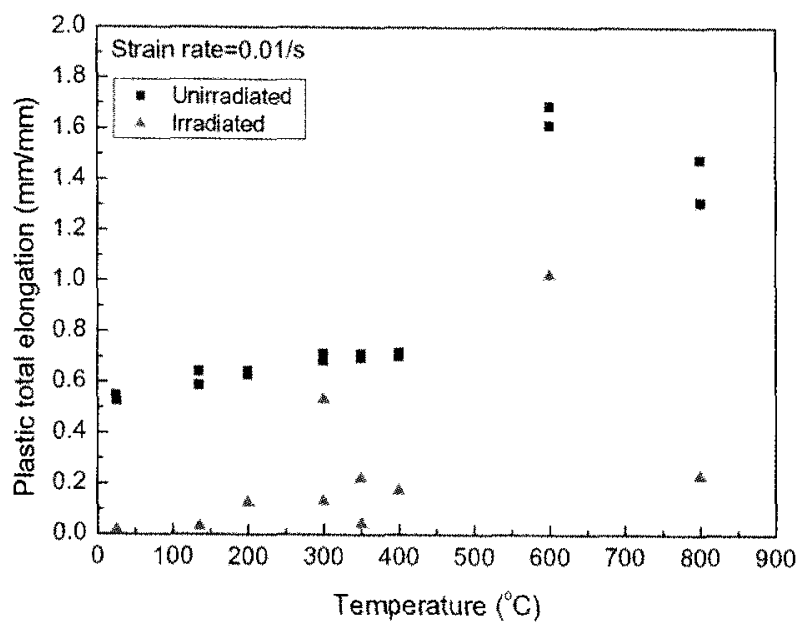

Fig. 14. Total Elongation of the Un-irradiated and High Burnup Fuel Cladding

inventory was estimated at about $40 \%$ of the total residual fission gases.

To investigate the mechanical properties of irradiated claddings, total elongation was evaluated as a measure of ductility. Figure 14 shows a comparison result of ductility of the high burnup Zircaloy-4 with unirradiated Zircaloy4. It is shown that total elongation increased with an increasing temperature. In particular, they abruptly increased at $600^{\circ} \mathrm{C}$, but became lower beyond this temperature. This peculiar behavior was also observed in the PROMETRA program, which is a mechanical property relevant test program in conjunction with the CABRI program for simulating a RIA [26].

The compression characteristics of high-temperature oxidized cladding and high burnup cladding were examined

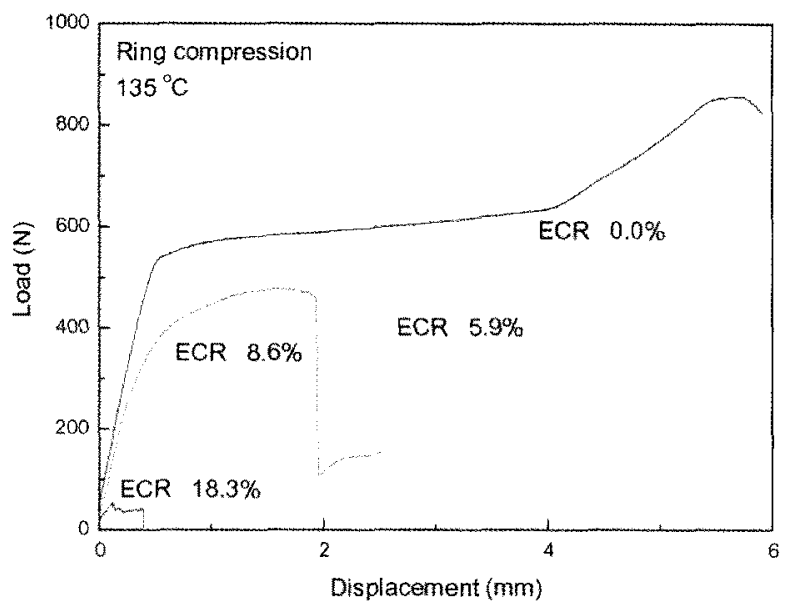

Fig. 15. Load-displacement Relations of Oxidized Zr Alloys $\left(135^{\circ} \mathrm{C}\right)$

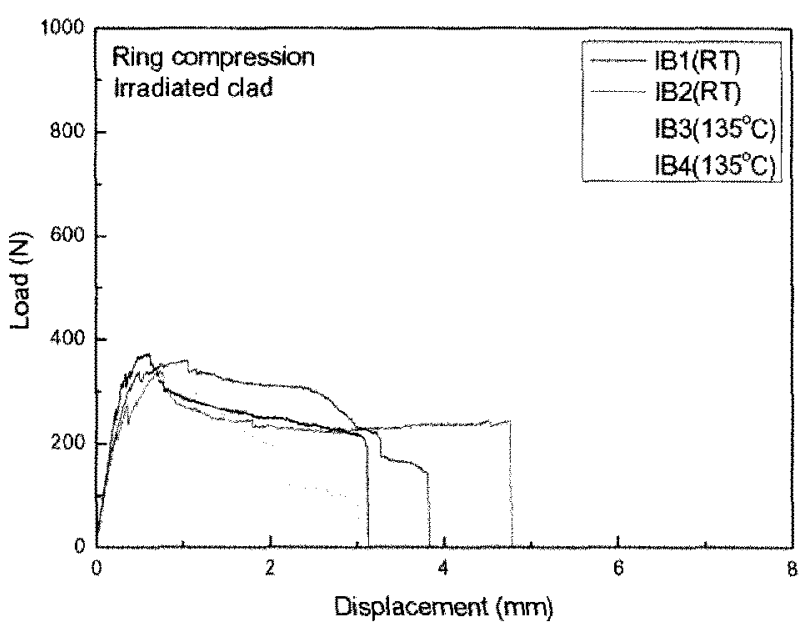

Fig. 16. Load-displacement Relations of Spent Fuel Cladding

at $135^{\circ} \mathrm{C}$, which is a saturated temperature by quenching in LOCA. The Hobson's ring compression tests [27] which formed the base of the US LOCA embrittlement criterion, focused on the cladding embrittlement characterization at that temperature. Hence, in this study the test temperature, $135^{\circ} \mathrm{C}$, was employed.

The results revealed that ultimate strength, the displacement (ductility) to fracture, and the energy to fracture decreased with increasing ECR of the specimen (Figure 15).In particular, the ductility to fracture and the energy to fracture were sharply decreased, which signifies that the ductility of $\mathrm{Zr}$ alloy cladding degraded significantly due to the decrease in load-bearing ligament thickness of cladding as the oxidation degree increased. The ring compression tests for spent fuel cladding were also performed at $25^{\circ} \mathrm{C}$ and $135^{\circ} \mathrm{C}$. The results are presented 


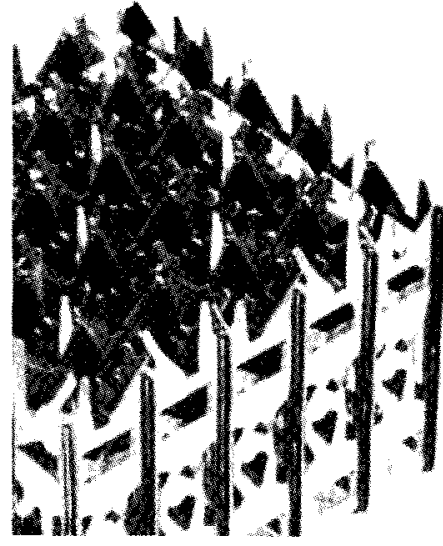

Fig. 17. $5 \times 5$ Spacer Grid with Theta Spring and Hybrid Mixing Vanes

in Figure 16. As shown in Figure. 16, while there was no significant difference in strength, the difference in ductility was observed. It can be deduced that the difference in ductility was caused by the difference in oxidation degree (ECR) and hydrogen content as an another embrittling parameter.

\subsection{Spacer Grid Technology}

\subsection{Foci of the R\&D Works}

Spacer grid is one of the key structural components of a nuclear fuel assembly. Rather than other components such as top and bottom end pieces, guide and center thimbles, it is closely related with fuel failure as well as thermal performance. Therefore, KAERI's research on the fuel assembly components has focused on the spacer grid technology in particular. Lots of patents on the shape of the grid have been registered especially for the springs and vanes. The theta $(\Theta)$ spring and the hybrid-mixing vane shown in Figure 17 can be referred to as a representative shape among them. On the other hand, experimental techniques and devices for a spacer grid have been developed: the fuel rod fretting wear, flow-induced fuel rod and grid vibration, grid impact, and characteristics of a grid spring, and so forth. Simulation of in-situ condition of the spacer grid was the first target during the development. Analysis technique was developed as well, especially for implementing a commercial finite element analysis code. The followings are the accomplishment of the experimental and analytical R\&D topics.

\subsubsection{Mechanical Test and Analysis}

The fretting wear of a fuel rod became one of the key root causes of fuel rod failure in the reactor. It can occur due to a coolant flow-induced vibration of the fuel rods. As the fuel rod vibrates, slipping between the fuel rod supports (e.g., springs and dimples) of the spacer grid and the fuel rod surfaces occurs inevitably and thus the

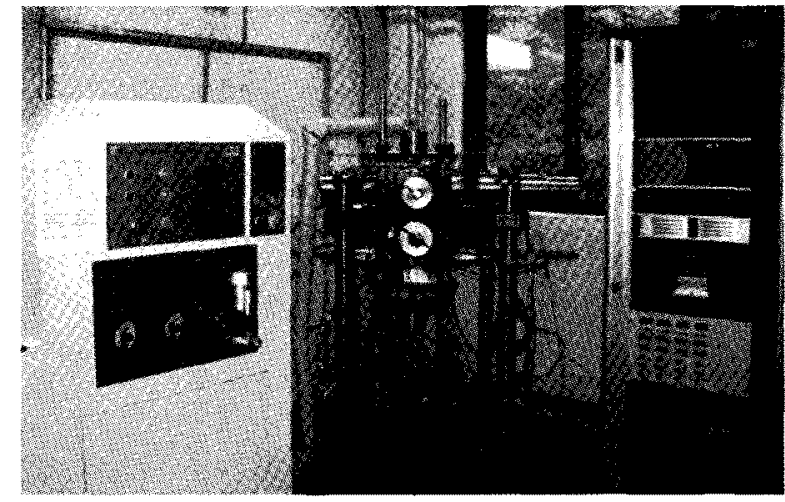

Fig. 18. Fretting Wear Simulator, FRETONUS

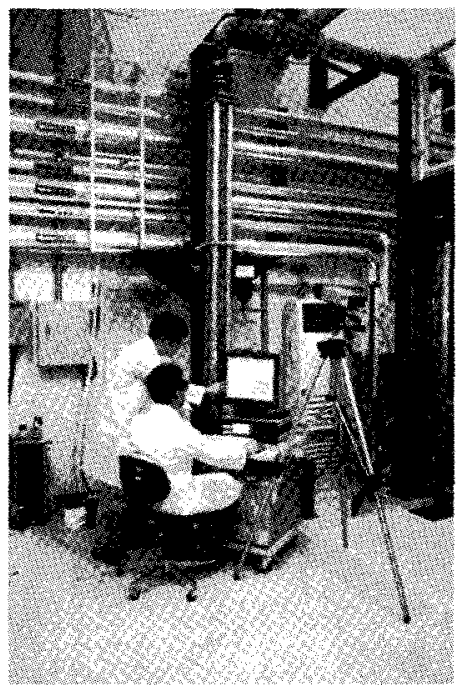

Fig. 19. Flow-induced Vibration and Pressure Drop Experimental Tester, FIVPET

fuel rod is susceptible to wear. Since the thickness of a fuel rod cladding tube is thin (around $0.6 \mathrm{~mm}$ ), perforation of the tube due to wear may happen. Radioactive fission gases inside the fuel rod are then released out to the reactor core. This problem should be overcome to achieve a high burn-up fuel with low leakage in the nuclear industry.

It is very difficult to solve the fretting wear problem since this kind of tribological failure is affected by many parameters such as contact force, contact shape, vibration amplitude, temperature, and chemical environment. So a fuel rod fretting wear simulator, named the FRETONUS (a fretting wear simulator of nuclear systems, Figure 18) has been developed to accommodate those parameters [28]. A two span length of a fuel rod was tested. One of the key features of it is that it can simulate the fuel rod motion due to the flow-induced vibration and the inreactor environment. After the wear scars were obtained, 
the depth and volume were measured by using the contact and non-contact surface profilometry. The wear coefficient of the workrate model [29] was often used to compare the wear severity. More research has been done on this fretting wear analysis and contact failure [30-32].

In relation to not only the fuel rod's fretting wear, but also to the fuel rod supporting characteristics, it was significantly important to investigate the fuel rod vibration feature due to the coolant. Also, the grid strap's high frequency vibration was an issue of the spacer grid technology. For the purpose of investigating those phenomena, a loop facility for the flow-induced vibration, named the FIVPET (Flow-Induced Vibration and Pressure drop Experimental Tester, Figure 19) was built [33]. A partial fuel assembly (often $5 \times 5$ array and a half height of a fuel assembly) was used together with instrumented fuel rods. The conditions of $80^{\circ} \mathrm{C}, 0.98$ $\mathrm{MPa}$ and $12 \mathrm{~m} / \mathrm{s}$ flow were generated by six impeller centrifugal type pumps. To measure the vibrations of this fuel rod and spacer grid, a laser doppler velocimeter was used. The measured vibration motion was used to compose an input signal of the FRETONUS. The flow-induced vibration phenomena corresponding to the developed spacer grid's difference were investigated [34-36].

One of the important functions of a spacer grid is to maintain a coolable geometry of a fuel assembly during any accidental conditions. It implies that the guile thimbles should not be deformed so that the control rod assembly can be inserted without any obstruction. Nowadays a $0.3 \mathrm{~g}$ seismic criterion has become the guideline of the impact strength. This was verified by using a self-developed pendulum type impact tester [37]. A full size spacer grid was tested. So far, the developed spacer grid assemblies in KAERI tested met the criteria $[38,39]$.

Fuel rod supporting capability is also important for the spacer grid. The springs and dimples were tested to obtain the force vs. displacement curves. The contact force was measured as a fuel rod specimen was inserted to the cell of the grid assembly. The force should be larger than the minimum supporting force of a fuel rod, lest it should fall down. The force was also an important parameter for the fretting wear failure.

In addition to the experimental technology, analysis tools were implemented and relevant technology was developed. Finite element analyses for the spring and dimple characteristics, and the impact strength, were successfully conducted. The analysis technology was efficiently used to modify the shape of the springs and dimples from their initial shapes without experiments.

It was also used to improve the contact shape designs of the spring. One of the successful achievements of them was the theta spring. A finite element analysis using a commercial code ABAQUS was carried out to simulate the contact area and shape between the fuel rod and the spring. Considering that the working range of the spring deflection when the fuel rod is loaded into the spacer grid cell was usually assumed to be around $0.3 \sim 0.4 \mathrm{~mm}$, it turned out that the contact area of the theta spring remained wide enough to support a fuel rod and to suppress the rod vibration [40].

Besides the above analyses of the grid mechanical performances, the analysis tools for the experimental results were also developed. For instance, software for the wear volume measuring was developed [41]. This efficient program was developed by using the MatLab platform and the Fast Fourier Transform algorithm, which considerably shortened the process time.

\subsubsection{Thermal Hydraulic Test and Analysis}

A major thermal hydraulic design aspect of spacer grid was to enhance the CHF(Critical Heat Flux) while maintaining the pressure drop as close to the existing value as possible. To accomplish the target, various steps have been required to examine the potential of the new design and confirm its performance. In the beginning stage a Computational Fluid Dynamics (CFD) analysis was vastly utilized to investigate the basic characteristics and optimization of several grid candidates with less time and expense. For a couple of competitive candidates some experiments were conducted to compare the major thermal hydraulic data like turbulent mixing, pressure drop, and CHF. Summaries for the above efforts are described in the following.

CFD analysis was performed to quickly investigate the heat and coolant flow behaviors downstream the candidate spacers [42]. By using the symmetry of the mixing-vane pattern as well as the flow, only four subchannels were modeled to reduce the size of the computation. For example, the CFD model for hybrid vanes used 4.8 million nodes with tetrahedrons, prisms, and hexahedrons [43]. Figure 20 illustrates the coolant mixing caused by the hybrid vane downstream of the spacer grid. The results show that the hybrid vanes

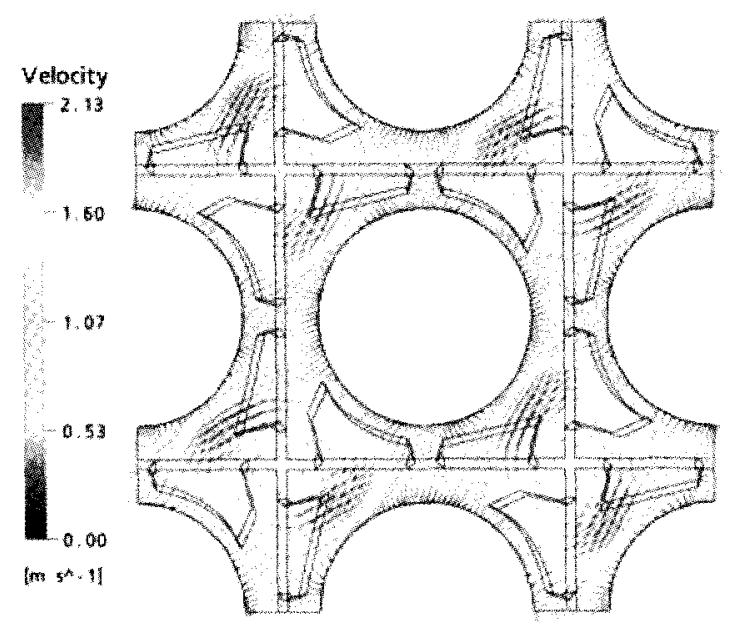

Fig. 20. Swirl and Crossflow Caused by the Hybrid Vane 
generated a large swirl inside the sub-channel and a small cross-flow between the adjacent sub-channels. In addition, a significant heat transfer enhancement on the fuel rod surface by the hybrid vane was also predicted, which would increase the DNB performance of the nuclear fuel assembly. As the computer capability is growing, this CFD approach is getting attention more and more in the nuclear fuel development field.

A wind tunnel test was conducted to measure the turbulent flow structure along the flow direction. The test section contained a $3 \times 3$ rod array with 8 times large enlarged rods to facilitate the detail measurements over a center sub-channel. The axial and lateral turbulent fluctuations were taken by a 2-D hot-wire anemometry and axial velocity distribution by Pitot tube at Re number of $1.2 \times 10^{5}$. In the Hybrid Mixing vane tests an apparently distorted large swirl inside the subchannel was observed, which helped greatly the bubble centering quickly from the heated rod surface by the centrifugal force [44]. It was attributed to the increase of the two-phase heat transfer as well as CHF.

The pressure drop tests were performed with a $5 \times 5$ rod bundled with various spacer grids. The tests were conducted at atmospheric pressure and temperature with water, which covered the Reynolds number from $10^{4}$ to $10^{5}$. The pressure loss coefficient of Hybrid Mixing Vane grid was 1.02 at $\operatorname{Re}=10^{5}$ which was slightly lower than or comparable with the conventional mixing vane grid [45].

Finally the Critical Heat Flux (CHF) tests were conducted with refrigerant $\mathrm{R}-134 \mathrm{a}$ to quantify the enhancements. There were two $5 \times 5$ rod bundles: one was a rod bundle with Hydrid Mixing vanes, while the other was a rod bundle without a mixing vane. The test matrix was in the ranges of the inlet pressure, $P_{\text {in }}=2000 \sim 3000 \mathrm{kPa}$, mass flux, $\mathrm{G}=1500 \sim 3000 \mathrm{~kg} / \mathrm{m}^{2} \mathrm{~s}$, and inlet subcooling, $\mathrm{h}_{\text {in }}=10 \sim 55 \mathrm{~kJ} / \mathrm{kg}$, which corresponded to the PWR operating conditions through a fluid-to-fluid modeling. From

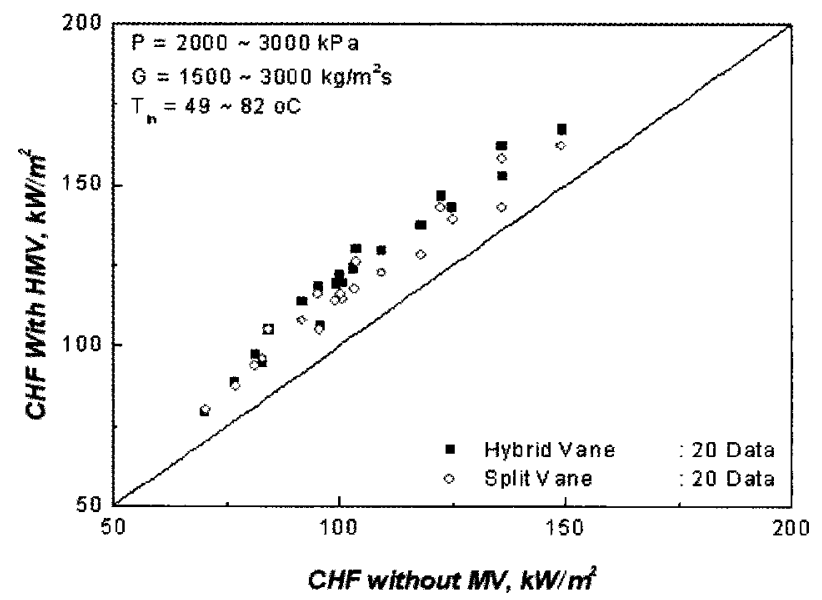

Fig. 21. CHF Enhancements of Hybrid Mixing Vanes the comparison results as shown in Figure 21, an average of the CHF increase for the hybrid mixing grids for 20 data sets was $18.2 \%$ higher than those for the no vane grids. Consequently, the Hybrid Mixing vane revealed an excellent CHF performance [46].

\subsection{Fuel Assembly Test Technology \\ 2.5.1 Mechanical Characterization Test}

When a new fuel is developed, it is compulsory to measure the mechanical characteristics of the fuel assembly to obtain the license. The necessary characterization items for this license are vibration, stiffness, and impact. As for vibration, natural frequencies, model shapes and critical damping ratios are the important outputs. The stiffness is obtained from the deflection at each grid location. Strains of the guide thimbles are also measured during the loading and unloading process for the stiffness measuring. The impact characteristic is for a possible case of a fuel assembly banging against an adjacent fuel assembly or a core baffle under the conditions of a seismic and LOCA. The test results of each item are to be used for the fuel assembly analysis model. Since it deals with a full size fuel assembly, the test facility is huge in size and needs very sophisticated data processing devices. The KAERI developed the tester successfully through the national $R \& D$ project $[47,48]$. The tester was named as the FAMeCT (Fuel Assembly Mechanical Characterization Tester, Figure 22).

After the construction and verification of the FAMeCT,

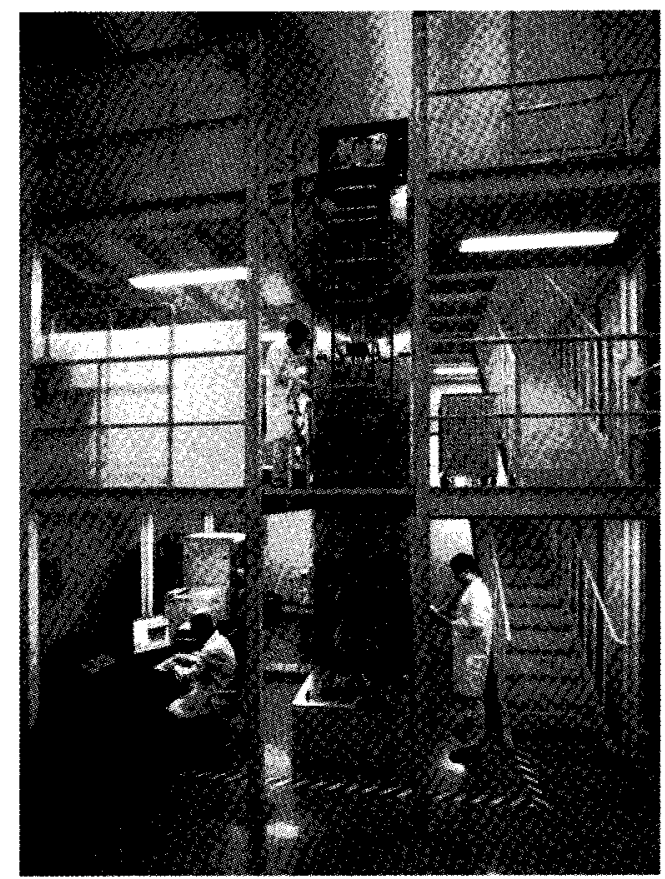

Fig. 22. Fuel Assembly Characterization Tester (FAMeCT) 
acquiring a credit of the quality and reliability of the data from a third party was attempted. It is very important since the data will be used to obtain a license of the fuel. So accreditation from the KOLAS (Korea Laboratory Accreditation Scheme) was pursued. Since the KOLAS joined the ILAC (International Laboratory Accreditation Corporation), the accreditation by KOLAS directly means international accreditation. Among the three test items, the stiffness test was already accredited by KOLAS in 2008. The vibration and impact tests are under examination by KOLAS. After completing the accreditation process, the capability of KAERI's fuel assembly mechanical tests will be further improved. A further closer approach to the nuclear fuel export is expected.

\subsubsection{Hydraulic Test}

The Hydraulic Test Loop (HTL) in Figure. 23 was established for pressure drop of fuel assembly components and lift-off flow along with a full scale fuel assembly. The design pressure is 30 bars and the maximum loop flow rate is $500 \mathrm{~m}^{3} / \mathrm{hr}$. The loop coolant was de-ionized water. The width of the flow housing is designed to have the same as the pitch of a fuel assembly in a core.

The pressure drop test provided the span wise pressure loss of a component in a fuel assembly. The locations of the pressure taps were determined to represent a suitable pressure loss of each component such as a bottom end piece, a spacer grid, a fuel rod, a top end piece, and a fuel assembly. The measured pressure loss of each component in a fuel assembly was used to determine the pressure loss coefficient. Pressure loss coefficients are important

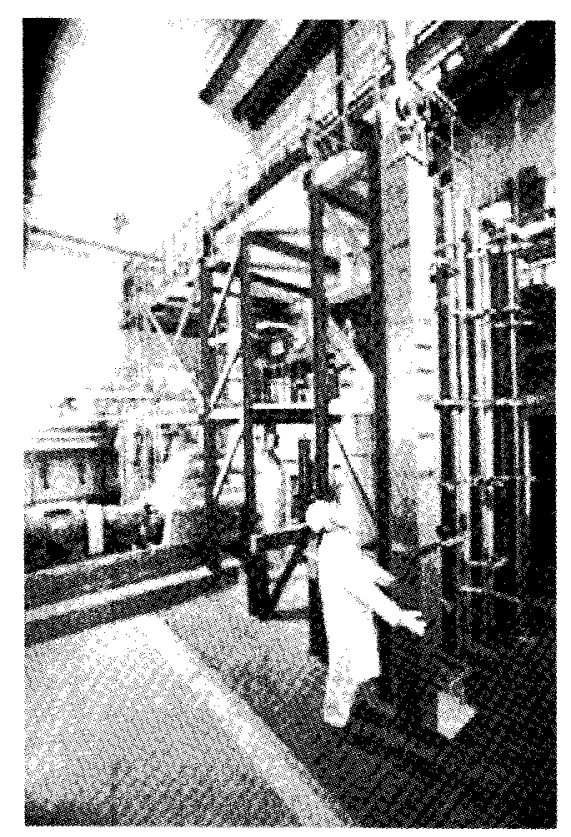

Fig. 23. HTL input to perform the design evaluation and safety analysis.

The lift-off test measured the flow rate at which the test bundle was lifted from the simulated core support plate. It happens when the hydraulic force by the coolant flow is equal to or greater than the net assembly weight in the water. This occurrence of a lift-off of the fuel assembly can be detected by a sudden change of the pressure loss in the bottom end piece region due to a flow area change. This test was performed at the coolant temperatures of 65 and $120^{\circ} \mathrm{C}$ without a hold down spring. The fuel assembly was uplifted at 321 and $341 \mathrm{~m}^{3} / \mathrm{hr}$ for 65 and $120^{\circ} \mathrm{C}$, respectively. The uplift flow rate difference with the coolant temperature was mainly due to a coolant density difference.

PLUTO in Figure 24 is a hydraulic compatibility test loop for transient core. In the test vessel two different types of full scale fuel assemblies were positioned side by side to simulate a transition core. The design pressure and temperature were 40 bars and $250{ }^{\circ} \mathrm{C}$, respectively. Four main circulation pumps can flow up to $1400 \mathrm{~m}^{3} / \mathrm{hr}$. In this facility, flow-induced rod vibration and long-term wear due to unbalanced local hydraulic characteristics between two different fuel assemblies were mainly investigated.

\subsection{MOX Fuel Technology}

Mixed oxide (MOX) fuel, manufactured by the mixture of $\mathrm{UO}_{2}$ powder and $\mathrm{PuO}_{2}$ powder, has been developed and extensively used in commercial Light Water Reactors (LWRs) for the last several decades in some European countries, and recently it has gained considerable attention due to the soaring uranium price. In addition, it is supposed to be implemented in both US and Russia as a means to dispose of weapon-derived plutonium. While LWR MOX fuel is not used in Korea at the moment, it could

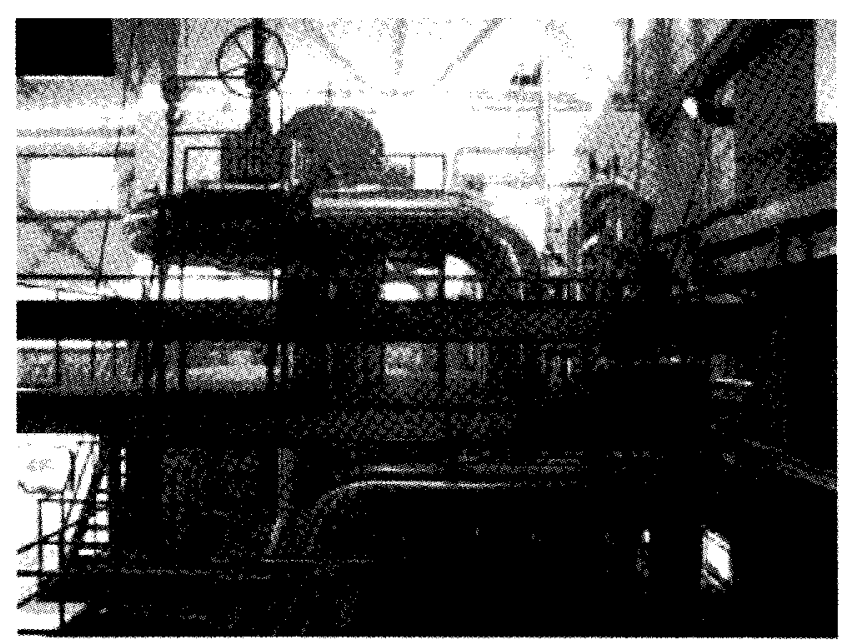

Fig. 24. PLUTO 
be one of the options in the future for back-end fuel cycle together with other options being actively developed within the framework of GEN-IV. In this regard, KAERI has been developing basic LWR MOX technology from 1997 in the area of fuel pellet fabrication and fuel and core performance analysis. Major achievements so far are described for the fuel pellet fabrication, the irradiation test of two MOX fuel rods in the Halden reactor within the framework of the OECD/NEA Halden Reactor Project, and the analysis of their in-reactor behavior during the test.

\subsubsection{Fabrication of MOX Fuel Pellets Rods for Irradiation}

Both $\mathrm{UO}_{2}$ and $\mathrm{MOX}$ fuel pellets are fabricated by the powder process such as mixing, milling, pressing, and sintering. The main differences between the two processes are the preparation of starting powder and a glove box system that require very special techniques to assure the safety and the efficiency in dealing with plutonium.

The achievement of mixing the homogeneity and the sinterability of a powder mixture is a key technology in fabricating a high performance MOX fuel. Figure 25 shows the dry continuous type attrition milling equipment developed for mixing $\mathrm{UO}_{2}$ powder and $\mathrm{PuO}_{2}$ powder [49]. The fabrication processes were then improved by the development of advanced technologies which included the fabrication method for large grain [50], pore-grain control of fuel pellet, scrap re-use, milling/granulation process, homogenous $\mathrm{Pu}$ distribution, and sintering in oxidizing atmosphere.

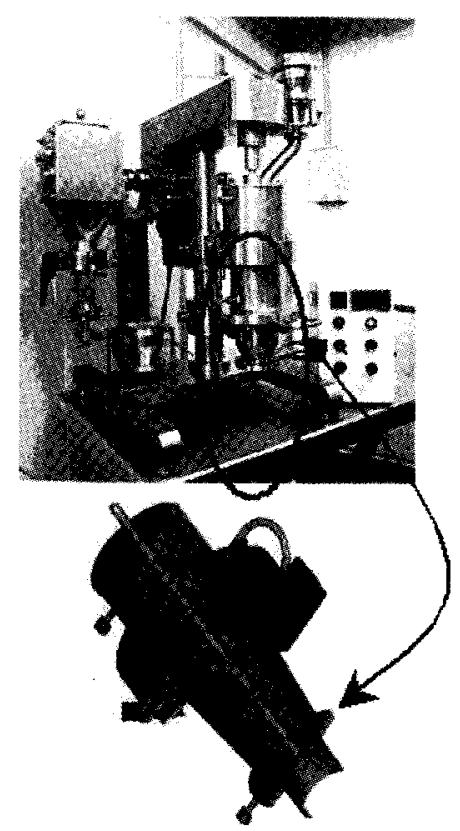

Fig. 25. The Dry Continuous Type Attrition Mill for Mixing $\mathrm{UO}_{2}$ and $\mathrm{PuO}_{2}$ Powder
The MOX fuel pellets to be used in the irradiation test were manufactured through an international collaboration between KAERI and PSI in Switzerland [51]. Figure 26 shows that the microstructure of the Ce-MOX and PuMOX pellets are homogeneous with an average grain size of $11 \mathrm{~mm}$ and a density of $95 \%$ T.D.

\subsubsection{Development of Fuel Performance Code for MOX Fuel}

MOX fuel is different from typical $\mathrm{UO}_{2}$ fuel in that it contains up to $10 \mathrm{wt} \%$ of $\mathrm{Pu}$ from the beginning. Due to the difference in microstructure caused by the addition of $\mathrm{Pu}$, the following features should be considered when analyzing MOX fuel with performance models for $\mathrm{UO}_{2}$ fuel: changes in thermo-mechanical properties such as thermal conductivity and thermal expansion coefficient, changes in radial power depression in a fuel rod as a function of $\mathrm{Pu}$ fissile content, changes in the mechanism of fission gas release resulting from the heterogeneous microstructure of MOX fuel depending on the manufacturing method, and high burn-up phenomena of fuel such as rim formation and thermal conductivity degradation.

Considering the above features of MOX fuel and high burn-up characteristics, a computer code COSMOS has been developed for the analysis of both $\mathrm{MOX}$ and $\mathrm{UO}_{2}$ fuel during the steady-state and transient operating conditions [52]. The main characteristics of COSMOS are described in $[53,54]$. When the $\mathrm{Pu}$-rich particle is divided

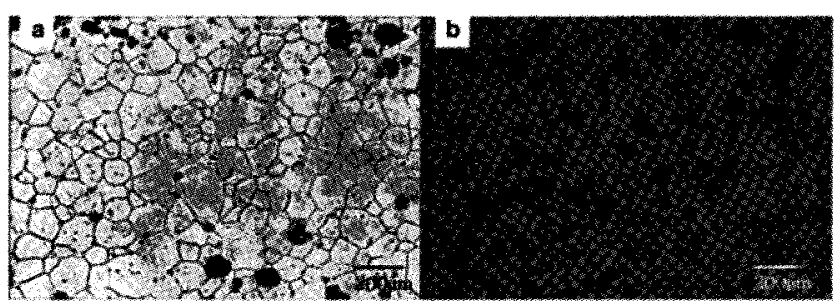

Fig. 26. Microstructure of (a) Ce-MOX and (b) Pu-MOX Pellets

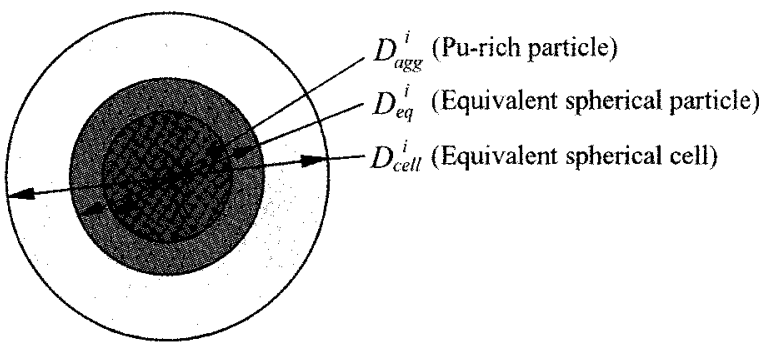

Fig. 27. An Equivalent Spherical Cell for a Pu-rich Particle Corresponding to i-th Group [53] 
into several groups according to their size, an equivalent cell for i-th group appears, as shown in Figure 27.

Difference in fission densities in the two regions is one of the dominant factors that cause different gas release behavior in the MOX and $\mathrm{UO}_{2}$ fuel. Various models have been developed, which included a thermal conductivity model [55,56], a new clad corrosion and creep model $[57,58]$. The pressure of the rim pores and the additional pellet swelling due to rim formation were modeled as a function of temperature, pellet average burn-up and pore radius [59]. COSMOS was tested with a number of experimental results obtained from some of the international fuel irradiation programs. It was found that the calculated results of COSMOS showed a good agreement with the measured data [60].

\subsubsection{Irradiation Test in the Halden Reactor}

The irradiation test of the two MOX fuel rods, which were fabricated in PSI through the cooperation of KAERI and PSI, started in June 2000 in the Halden Reactor and was completed in October 2006. During the irradiation, good integrity of the test fuel rods was shown with no faulty signals from the instrumentations [61]. The average burnup for the two MOX fuel rods reached about $50 \mathrm{MWd} / \mathrm{kgHM}$.

The maximum fuel temperature was estimated to be around $1500^{\circ} \mathrm{C}$ at the mid-plane of the fuel stack of the MOX-TF. While MOX-TF showed $\sim 2 \%$ densification, MOX-ET displayed $\sim 1 \%$. However, since both MOX fuel rods were fabricated by the same manufacturing route in the same campaign, the same maximum densification of $2 \%$ was applied for the analysis by COSMOS. A swelling rate of $0.85 \%$ per $10 \mathrm{MWd} / \mathrm{kgHM}$ was derived from the normalized rod internal pressure during the period before fission gas release occurred significantly.

As for the MOX-TF, the measured and calculated fuel temperature by COSMOS at the thermocouple tip are compared in Fig. 28, showing very good agreement between measurement and calculation. The recovery effect of the thermal conductivity [62] was considered for this analysis due to the observed significant fission gas release.

The rod internal pressures predicted by COSMOS were compared with the measured ones in Figure 29. A substantial fission gas release was observed and the rod internal pressure enhanced by a substantial fission gas release was simulated well by COSMOS as shown in Figure 29. In the case of MOX-ET, the thermal behavior and rod internal pressure were also predicted well as in the MOX-TF. It is noted that precise prediction by COSMOS was achieved by integrating accurate fuel performance models such as the thermal conductivity, fission gas release, and fuel geometrical changes .

The basic PIE for the two test fuel rods - visual inspection, gamma scanning, gas puncturing, ceramography - had been carried out in Kjeller Institute and more detailed tests, such as SEM and EPMA, will be performed in PSI of Switzerland. The PIE data obtained so far reveals that the microstructure of the KAERI's two fuel rods was comparable to those of the BNFL one.

\section{PWR FUEL DEVELOPMENTS BY KNF}

KNF was established in 1982 and has been supplying all of the nuclear fuels for the nuclear power plants in Korea since 1989. KNF has been fabricating both PWR and PHWR (CANDU) fuels with a production capacity of $350 \mathrm{MTU} /$ year and $400 \mathrm{MTU} /$ year, respectively and recently increased its PWR fuel production capacity up to $550 \mathrm{MWD} /$ year, responding to the increasing demand of PWR fuels.

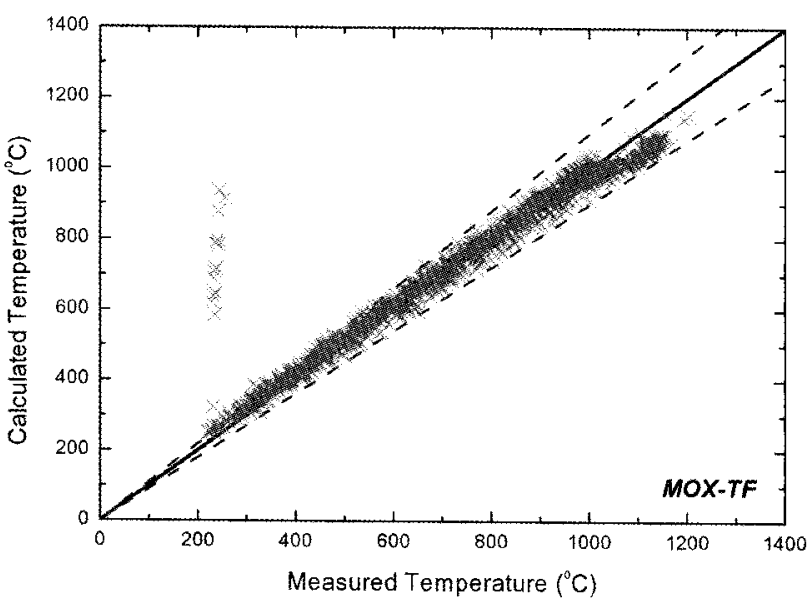

Fig. 28. Comparison of the Calculated Centerline Temperatures with the Measured Ones for the MOX-TF

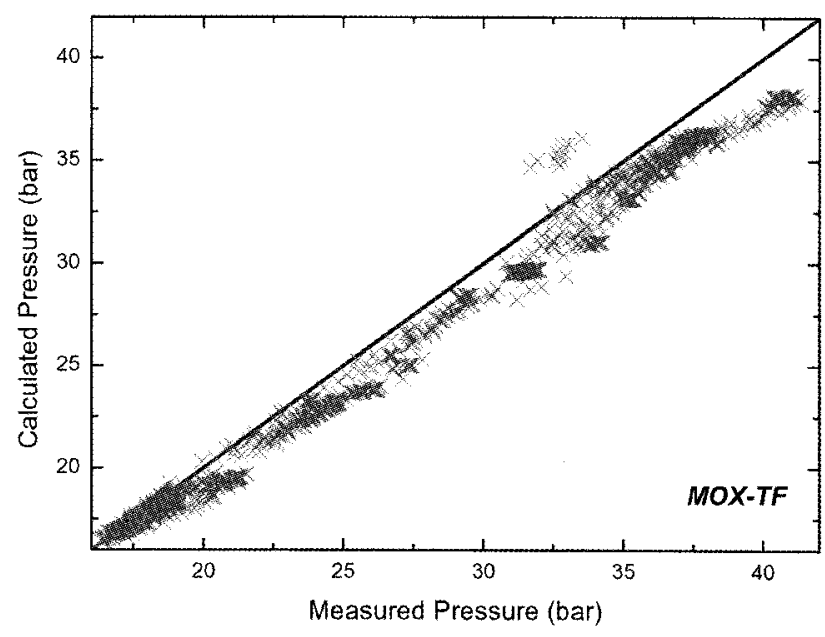

Fig. 29. Comparison of the Calculated Rod Internal Pressures with the Measured Ones for the MOX-TF 
In this paper, the development activities and results in commercial PWR fuels in KNF are described, including fuel technology localization and advanced fuel developments such as PLUS7 and ACE7. Operating experiences and fuel performance are also discussed.

\subsection{PWR Fuel Development Strategy}

The commercial nuclear fuel technologies have been developed by using a step-by-step strategic approach. At first, KNF established nuclear fuel technologies, based on those transferred from foreign fuel vendors, including fuel and non-fuel components localization such as $\mathrm{UO}_{2}$ powder, fuel pellet, and structural components. Since the late 1990 's, KNF has continued to focus on developing PWR fuels that will meet the challenge of increasing fuel duty requirements in Korea. The design objectives include high burn-up and high thermal performance as well as high reliability and margin increase such as extended fuel burn-up, DNB margin increase, increasing debris-filtering efficiency, preventing incomplete RCCA insertion, and enhancing neutron economy. Recent advanced fuel development activities include the $16 \times 16$ PLUS7, jointly developed with Westinghouse, for use in the Optimized Power Reactor 1000 (OPR 1000) in Korea. Four LTAs have successfully completed three cycles' irradiation and the region implementation has been occurring since June, 2006. For use in $16 \times 16$ and $17 \times 17$ Westinghouse type plants, KNF has developed next generation fuel assemblies, ACE7, jointly with Westinghouse (WEC) and Industrias Nucleares do Brasil (INB). Four LTAs of $16 \times 16$ ACE7 have also successfully completed three cycles' of irradiation and the region implementation has been occurring since July, 2008. For $17 \times 17$ ACE7, their LTAs are under 3rd cycle irradiation with a good performance and region implementation that started in February 2009. Lastly, to be more competitive than ever and to move into the world fuel markets, the "X-Gen Fuel Project" started in the year 2005 and the LTA development is scheduled to be completed in late 2011 .

\subsection{Nuclear Fuel Technology Localization}

KNF was established in 1982 to supply nuclear fuels for the nuclear power plants in Korea and has been supplying all of the nuclear fuels for the PWRs and PHWRs in Korea since 1989 and 1997, respectively.

Based on the various technologies transferred from the former Siemens/KWU, the former Combustion Engineering and Westinghouse Electric Companies, the commercial nuclear fuel technologies have been established which includes fuel component localization such as $\mathrm{UO}_{2}$ powder, fuel pellet, and structural components. KNF's current business areas may be summarized as follows:

- $\mathrm{UO}_{2}$ power production

- Design and fabrication of both PWR and PHWR fuel

- Core design and safety analysis for PWR
- Nuclear fuel service including fuel examination, repair, ultrasonic-driven crud cleaning, etc.

- Research and development for nuclear fuel, design codes, manufacturing process, etc.

KNF has supplied PWR fuels of 4,824MTU and performed reactor core design and safety analysis for 180 reloads and 8 initial cores as of the end of 2008 . KNF has also provided engineering services for more operational margin and better economic efficiency of nuclear power generation such as power up-rating and relaxed axial offset control. KNF also provides nuclear fuel services to improve the reliability of nuclear power plants and to shorten the refueling outage period, and to reduce radiation exposure. The nuclear fuel services cover reactor coolant activity analysis, visual inspection of fuel, repair and reconstitution of damaged fuel, poolside examination of irradiated fuel, and ultrasonic fuel cleaning which is used for removing crud deposited at the cladding surface. KNF has accumulated a lot of nuclear fuel service experiences such as fuel reconstitution due to a cracked spring screw or a leaky fuel rod, poolside examination of LTA, and other fuel surveillance programs.

KNF has also up-to-date nuclear fuel manufacturing facilities with the annual production capacity of 350 ton$U$ for PWR fuel and with that of 400 ton- $U$ for PHWR fuel. For PWR fuel, the wet process (AUC) and the dry process (DC) have been operating since 1988 and 1998, respectively. Recently KNF increased the PWR fuel production capacity up to $550 \mathrm{MWD} / \mathrm{MTU}$, responding to eight more PWRs to be built by the year 2017. In addition, KNF launched a joint development program with WEC to develop Zirconium alloy tube manufacturing technology in 2004 and KNF's Techno Special Alloy (TSA) has started its commercial production early 2009. Based on the good in-reactor operating experience of the nuclear fuel, KNF has reliable capability to supply all kinds of fuel and non-fuel components of PWR and PHWR fuels.

\subsection{Advanced Fuel Assembly Developments 3.3.1 Nuclear Industry Trends}

In Korea, fuel discharge burnup has increased to about $48 \mathrm{GWD} / \mathrm{MTU}$ batch average and up to the present licensing limit of $60 \mathrm{GWD} / \mathrm{MTU}$ peak rod average burnup. For the Korean advanced fuel designs discussed in this paper, the advanced fuel designs will be capable of up to $55 \mathrm{GWD} / \mathrm{MTU}$ batch average discharge burnups and beyond the present licensing limit of $60 \mathrm{GWD} / \mathrm{MTU}$ peak rod average burnup.

Core reload design and economic analyses show that PWRs can derive significant benefits by increasing burnup of their fuel above the currently licensed values. To protect the reactor coolant system, new chemistry programs are being implemented that expose the fuel to new and possibly more severe coolant chemistry. These operating modes reduce the design margin of the operation closer to design limits or require new designs that provide 
additional margin. While today's fuel products can often be pushed into more extreme operational modes by trade offs with operational parameters such as peaking factors, fuel cycle economics are usually impacted. Advanced products will provide more design margin, which can be used to maximize fuel cycle economic benefits.

\subsubsection{Development Objectives and Design Features}

A recent series of advanced fuel development activities include the $16 \times 16$ PLUS7 for use in the Optimized Power Reactor 1000 (OPR 1000) in Korea. Four LTAs have successfully completed three cycles' irradiation and the region implementation has been occurring since June 2006. KNF has developed next generation fuel assemblies, ACE7, jointly with Westinghouse (WEC) and Industrias Nucleares do Brasil (INB) for use in $16 \times 16$ and $17 \times 17$ Westinghouse type plants. Four LTAs of $16 \times 16$ ACE7 have also successfully completed three cycles' irradiation and the region implementation has been occurring since July 2008 . For $17 \times 17$ ACE7, their LTAs are under 3rd cycle irradiation with a good performance and region implementation that has been taking place since February, 2009.

The advanced fuel assembly design for the OPR 1000 , $16 \times 16$ and $17 \times 17$ Westinghouse type plants in Korea had the following program objectives:

- Batch average and peak rod average discharge burnup greater than $55 \mathrm{GWD} / \mathrm{MTU}$ and $75 \mathrm{GWD} / \mathrm{MTU}$, respectively

- More than 20\% increase in DNB margin and more than $10 \%$ increase in overpower margin over existing fuel assembly

- Through-grid dynamic buckling strength and dynamic stiffness sufficient to high seismic load

- Defect free against debris and grid-to-rod fretting wear
The PLUS7 fuel design features are summarized in Table 2 and its overall configuration is shown in Figure 30 . PLUS 7 design is a former CE type $16 \times 16$ array having 236 fuel rods, 12 spacer grids, 4 big guide thimble tubes, and one instrumentation tube. The PLUS7 design features include a fuel rod with high burnup capability, an easy removable top nozzle, a reduced rod bow top grid, mid grids with mixing vanes, a fretting wear resistant bottom grid, a debris filter grid, a bottom nozzle with

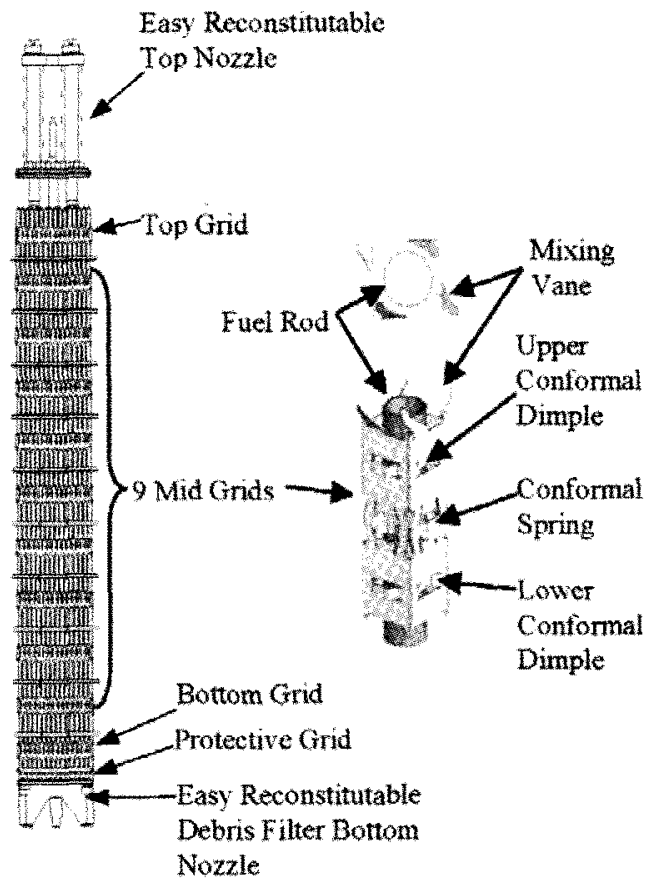

Fig. 30. PLUS7 Fuel Assembly

Table 2. Main Design Features of $16 \times 16$ PLUS7

\begin{tabular}{|c|c|c|c|}
\hline Item & Guardian Fuel & PLUS 7 & 7 Benefits of PLUS 7 \\
\hline Fuel Rod & Zry-4 Clad & $\begin{array}{c}\text { ZIRLO }{ }^{\mathrm{TM}} \text { Clad Optimized Rod } \\
\text { Dia. Axial Blanket }\end{array}$ & $\begin{array}{l}\text { 1. High Burnup ( }>75 \text { GWD/MTU) } \\
\text { 2. Neutron Economy }\end{array}$ \\
\hline Mid Grid & No Mixing Vane & $\begin{array}{c}\text { ZIRLO }^{\mathrm{TM}} \text { Mid Grid With } \\
\text { Mixing Vane Conformal Surface } \\
\text { Spring \& Dimple }\end{array}$ & $\begin{array}{l}\text { 3. DNB Margin }(>20 \%) \\
\text { 4. Fretting Wear Resistance } \\
\text { 5. Seismic Resistance }\end{array}$ \\
\hline Guide Thimble & Zry-4 with TIG welding & ZIRLO $^{\text {TM }}$ with Spot Welding & 6. Manufacturing Productivity \\
\hline Bottom Nozzle & Standard & Small Hole & \multirow{3}{*}{ 7. Debris Filtering } \\
\hline Protective Grid & Guardian Grid & Protective Grid & \\
\hline End Plug & STD End Plug & Long Solid End Plug & \\
\hline
\end{tabular}


small holes and slots for debris filtering. The key design features of the PLUS7 fuel may be described as follows: Firstly, the fuel rod diameter was reduced from 9.70 to $9.50 \mathrm{~mm}$ to compensate for the pressure drop increase caused by mid-grids with mixing vanes and to enhance the neutron economy by optimizing the moderation ratio of water-to-uranium. A detailed fuel management study indicated that more than four million dollars may be saved at each cycle of 18 months when the reference fuel was replaced with the PLUS7 fuel. Secondly, conformal springs/dimples of mid-grids, as shown in Figure 30, were invented to increase grid-to-rod fretting wear resistance with an increase of grid-to-rod contact area. Thirdly, a multi-defense device against debris was introduced. Lastly, Zircaloy-4 material was replaced by one of the $\mathrm{Zr}-\mathrm{Nb}$ alloys for cladding tubes in order to guide the thimble tubes and mid-grid strips to achieve high burn-up capability greater than the current licensed peak rod burn-up of 60 GWD/MTU [63].

The $16 \times 16$ ACE7 fuel design features are summarized in Table 3 and its overall configuration is shown in Figure 31(a). The major focus for the $16 \times 16$ Westinghouse type fuel development program was to update the 16STD, which is being utilized at the Angra-1, the Kori \#2, and the Krsko sites. Basically, the 16STD design contains a non-optimized fuel rod diameter (i.e. $9.5 \mathrm{~mm}$ OD fuel rods) for the fuel rod pitch, non-neutronic efficient components (i.e. Inconel Mid grids), no Intermediate Flow Mixer (IFM) grids, non-optimized guide thimble tubes (i.e. swaged tube dashpot), a non-debris filtering bottom nozzle, and mechanical design features that have not been updated to allow for top-down fuel rod reconstitution (i.e. welded top nozzle to skeleton).

The $16 \times 16$ ACE7 was designed for peak rod average burn-ups of up to $75 \mathrm{GWD} / \mathrm{MTU}$ and will use an optimized fuel rod diameter (i.e. $9.1 \mathrm{~mm}$ OD $\mathrm{Zr}-\mathrm{Nb}$ alloy fuel rods),

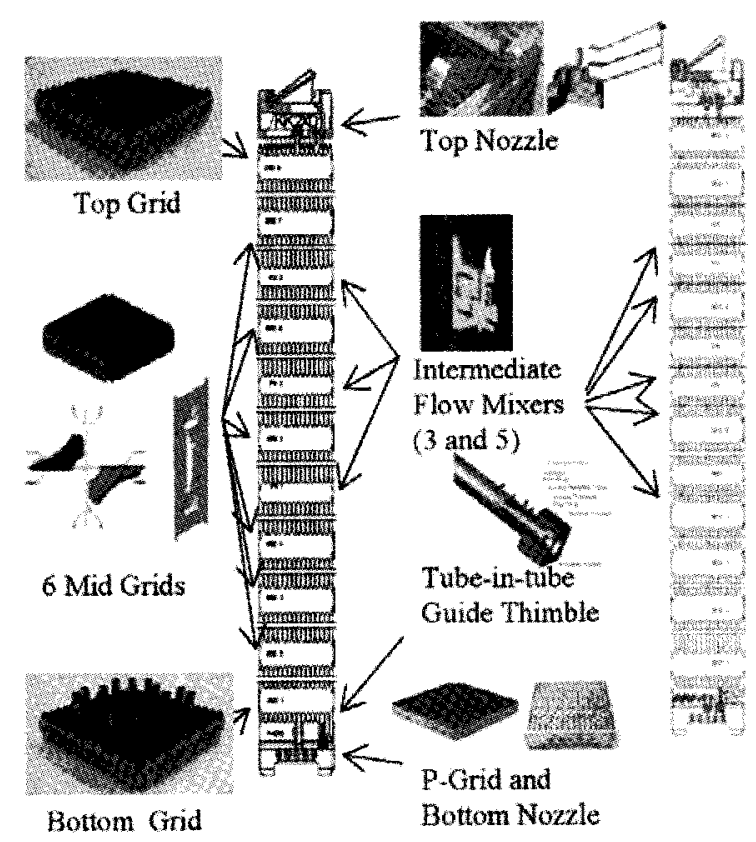

(a) $16 \mathrm{ACE} 7^{\mathrm{TM}}$

(b) $17 \mathrm{ACE} 7^{\mathrm{TM}}$

Fig. 31. ACE7 Fuel Assembly

Table 3. Main Design Features of 16x16 ACE7

\begin{tabular}{|c|c|c|c|}
\hline Item & 16STD & $16 \times 16 \mathrm{ACE} 7$ & 7 Benefits of ACE 7 \\
\hline Fuel Rod & Zry-4 & $\begin{array}{c}\text { ZIRLO }^{\mathrm{TM}} \text { Clad Optimized Rod } \\
\text { Dia. Axial Blanket }\end{array}$ & $\begin{array}{l}\text { 1. High Burnup ( }>75 \text { GWD/MTU) } \\
\text { 2. Neutron Economy }\end{array}$ \\
\hline Mid \& IFM Grid & $\begin{array}{l}\text { Inconel Mld Grid } \\
\text { No IFM }\end{array}$ & $\begin{array}{c}\text { ZIRLO }^{\mathrm{TM}} \text { Mid Grid Optimized } \\
\text { Mixing Vane I-Spring } \\
3 \text { IFM's }\end{array}$ & $\begin{array}{l}\text { 3. DNB Margin }(>20 \%) \\
\text { 2. Neutron Economy } \\
\text { 4. Fretting Wear Resistance }\end{array}$ \\
\hline Guide Thimble & Zry-4 with Swaged Dashpot & ZIRLO $^{\mathrm{TM}}$ Tube-in-Tube & 5. Robust \& IRI Free \\
\hline Top Nozzle & TIG Welded to Skeleton & Modified ICTN with RTN & $\begin{array}{l}\text { 6. Reconstitutible \& Spring } \\
\text { Screw Failure Free }\end{array}$ \\
\hline Bottom Nozzle & Standard & DFBN & \multirow{3}{*}{ 7. Debris Filtering } \\
\hline Protective Grid & None & Protective Grid & \\
\hline End Plug & STD End Plug & Long Solid End Plug & \\
\hline
\end{tabular}


neutronic efficient components (i.e. $\mathrm{Zr}-\mathrm{Nb}$ alloy mid grids), mid grids with I-spring design to enhance fretting wear resistance, $\mathrm{Zr}-\mathrm{Nb}$ alloy IFM grids to improve DNB margin, robust $\mathrm{Zr}-\mathrm{Nb}$ alloy guide thimble tubes (i.e. tubein-tube dashpot) from an IRI standpoint, debris filter bottom nozzle and Protective Grid (P-Grid) to enhance debris filtering and capturing efficiency, and updated mechanical design features that allow for top-down fuel rod reconstitution and spring screw failure free (i.e. removable Integral Clamp Top Nozzle). The $16 \times 16$ joint development program relies on the successful transition core experience of $17 \times 17$ Standard fuel assembly (17STD) which contained $9.5 \mathrm{~mm}$ OD fuel rods, Inconel Mid Grids, and welded top nozzle to skeleton to that of $17 \times 17$ Optimized Fuel Assembly (17OFA) which contained $9.1 \mathrm{~mm}$ OD fuel rods, $\mathrm{Zr}$-Nb alloy Mid Grids, and a removable top nozzle and to that of $17 \times 17$ Vantage 5 fuel assembly (17V5) which contained the same features as 17OFA but also had IFM's in the upper 3 spans of the 17OFA fuel assembly $[64,65]$.

The $17 \times 17$ ACE7 fuel design features are summarized in Table 4 and its overall configuration is shown in Figure 31 (b). For the $17 \times 17$ ACE7 fuel design, the effort was focused on providing the design margin to deal with the design considerations discussed earlier that are required for the high duty operation associated with higher energy cores (i.e. high burnup, high capacity factors, long cycles, power upratings, and adverse coolant chemistry). Sufficient margin must be provided to assure flawless fuel performance. Even though all design areas were considered, the focus on power upratings required special attention on thermal performance. In the past, thermal performance typically meant DNB and LOCA considerations. With the advent of crud related phenomena such as Crud Induced Power Shift (CIPS) and crud related leaks at several plants, increased heat flux in PWR fuel assemblies poses new risks that must be accounted for. This new dimension involves local sub-cooled boiling and the interaction with crud depositing coolant chemistry conditions that can lead to CIPS and accelerated corrosion. Prevention of crud deposition is one key to avoid these new phenomena.

In designing fuel to prevent crud deposition, a key consideration is the mass evaporation rate or boiling rate, which can be directly related to temperature. Nonuniformity of the temperature distribution around a fuel rod was caused by flow field variations due to bundle geometry and support structure (i.e. spacer grids). Although the temperature distribution was determined by Computational Fluid Dynamics (CFD) analyses, it resembled crud patterns found in fuel examinations. An ongoing aspect of advanced fuel development is to reduce the temperature variation and levels in these distributions $[64,65]$.

\subsubsection{Out-of-pile Tests}

Mechanical and thermal hydraulic performances of the advanced fuel assembly had been verified by a wide spectrum of out-of-pile tests such as the spacer grid dynamic buckling test, the spacer grid vibration test, the

Table 4. Main Design Features of $17 \times 17$ ACE7

\begin{tabular}{|c|c|c|c|c|}
\hline Item & $17 \mathrm{~V} 5 \mathrm{H}$ & 17RFA & $17 \times 17 \mathrm{ACE} 7$ & 7 Benefits of ACE 7 \\
\hline Fuel Rod & $\begin{array}{l}\text { Zry-4 } \\
\text { Axial Blanket }\end{array}$ & $\begin{array}{c}\text { ZIRLO }^{\mathrm{TM}} \\
\text { Axial Blanket }\end{array}$ & $\begin{array}{l}\text { Optimized ZIRLO } \\
\text { Axial Blanket }\end{array}$ & $\begin{array}{l}\text { 1. High Burnup } \\
\text { (>75 GWD/MTU) }\end{array}$ \\
\hline $\begin{array}{l}\text { Mid \& IFM } \\
\quad \text { Grid }\end{array}$ & $\begin{array}{c}\text { Zry-4 } \\
\text { Diagonal Spring } \\
3 \text { IFMs }\end{array}$ & $\begin{array}{c}\text { ZIRLO }^{\mathrm{TM}} \text { Diagonal } \\
\text { Spring Modified MV } \\
3 \text { IFMs }\end{array}$ & $\begin{array}{l}\text { Optimized ZIRLO }{ }^{\mathrm{TM}} \mathrm{I}- \\
\text { Spring Optimized MV } \\
5 \text { IFMs }\end{array}$ & $\begin{array}{l}\text { 2. DNB Margin }(>20 \%) \\
\text { 3. Margin for CIPS } \\
\text { 4. Fretting Wear Resistance }\end{array}$ \\
\hline Guide Thimble & $\begin{array}{c}\text { Zry-4 with } \\
\text { Swaged Dashpot }\end{array}$ & $\begin{array}{c}\text { ZIRLO }^{\text {TM }} \text { Thicker } \\
\text { G/T(Swaged Dashpot) }\end{array}$ & $\begin{array}{c}\text { Optimized ZIRLO } \\
\text { Thicker G/T (Tube-in-Tube) }\end{array}$ & 5. Robust \& IRI Free \\
\hline Top Nozzle & RTN & RTN & $\begin{array}{l}\text { Modified ICTN } \\
\text { with RTN }\end{array}$ & 6. Spring Screw Failure Free \\
\hline Bottom Nozzle & DFBN & DFBN & DFBN & \multirow{3}{*}{ 7. Debris Filtering } \\
\hline Protective Grid & None & Protective Grid & Protective Grid & \\
\hline End Plug & STD End Plug & Long End Plug & Long End Plug & \\
\hline
\end{tabular}


Table 5. Summary of the Out-of-pile Verification Tests

\begin{tabular}{l|l}
\hline \multicolumn{1}{c|}{ Test Items } & \multicolumn{1}{c}{ Objectives } \\
\hline Spacer Grid (SG) Vibration Test & Check fuel integrity against high frequency SG vibration \\
\hline Fuel Assembly (FA) Vibration Test & Check fuel integrity against low frequency FA vibration \\
\hline FA Endurance Test & Check fuel integrity against grid-to-rod fretting wear \\
\hline SG Spring \& Dimple Fretting Wear Test & Obtain fretting wear-related basic parameters \\
\hline FA Pressure Drop Test & Check hydraulic compatibility between advanced fuel and the reference fuel \\
\hline Critical Heat Flux (CHF) Test & Evaluate overpower margin \\
\hline SG Dynamic Bucking Strength Test & Evaluate seismic load capability \\
\hline Debris Filtering Test & Evaluate debris filtering efficiency \\
\hline
\end{tabular}

Vibrometer Results - Magnitude

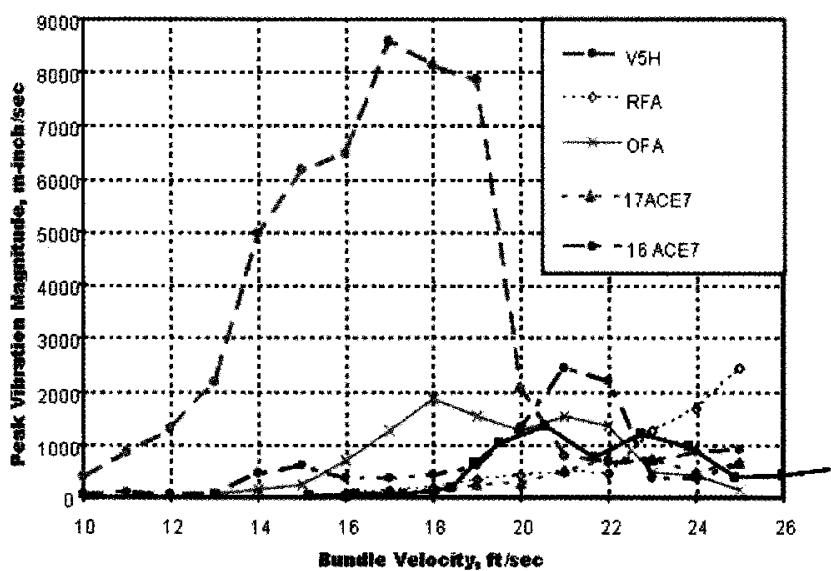

Fig. 32. High Frequency Vibration Test with Small Scale Test Assembly

fuel assembly vibration and wear tests, the fuel assembly pressure drop test and critical heat flux test, etc, while burn-up-dependent performances have been verified through in-reactor verification tests of four LTAs in the commercial PWR reactor.

The PLUS7 and ACE7 development programs have successfully completed a rigorous design and out-of-pile tests which has met or exceeded all of the design objectives that were determined at the start of the program. Table 5 summarizes the test objectives and typical test results are shown in Figures 32 and 33 [65,66].

\subsubsection{In-reactor Verification Tests}

Four LTAs of each advanced fuel assembly were manufactured by qualified processes that were exactly the same as those being used for the existing commercial fuel manufacturing at KNF. Four LTAs were loaded in Ulchin \#3, Kori \#2, and Kori \#3, respectively and irradiated

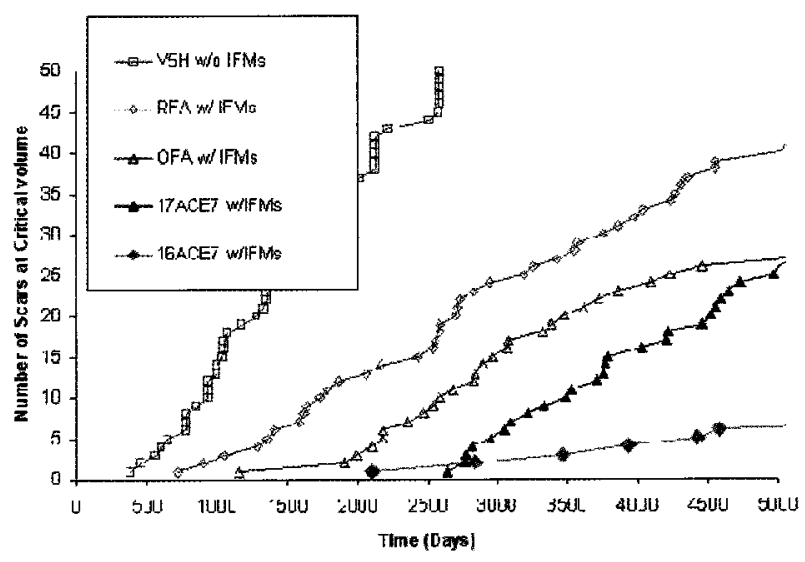

Fig. 33. Fuel Assembly Fretting Wear Test (Fuel Rod Leak Prediction Based on the 500 hour Test Results)

three cycles. The four LTAs were loaded in symmetric positions in the core and were located at the vicinity of the shroud, at the near center and in the middle zone for the first, the second, and the third cycles, respectively.

During the fuel outage period after each irradiation cycle, visual examinations were performed on four LTAs using the high-density camera. More accurate measurements were performed using four measurement equipments: equipment for dimensional measurement, Linear Variable Differential Transducer equipment (LVDT) for grid width measurement, another LVDT for rod outer diameter measurement, and an Eddy Current Test equipment (ECT) for rod oxide thickness measurement. Figure 34 shows the layout of poolside examination system [67].

\subsubsection{In-reactor Test Results and Discussion}

The visual examinations on all LTAs showed that top nozzle springs, fuel rod welding integrity, the fuel cladding and grids were in good condition. The analyses of power history and coolant activity show that the LTAs were 


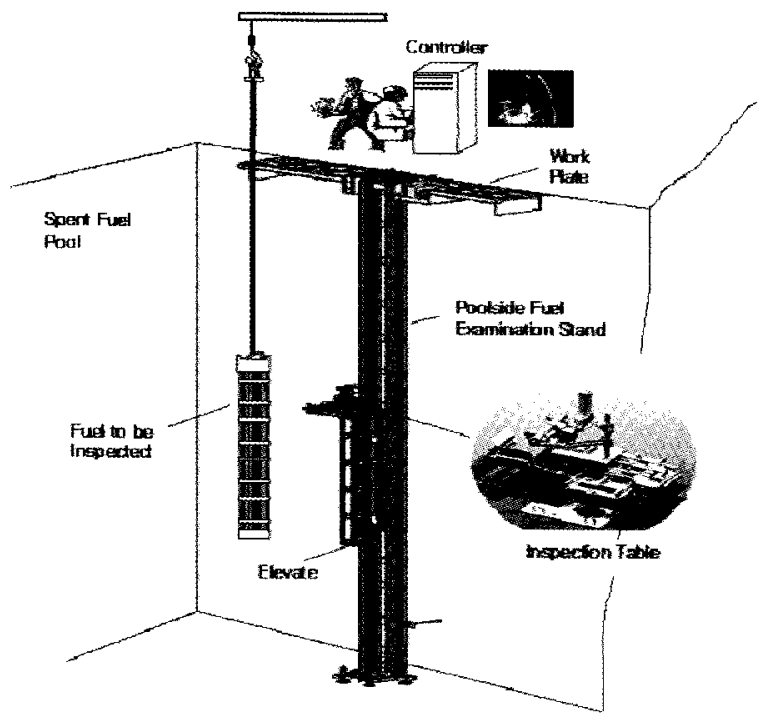

Fig. 34. Layout of Poolside Examination System

irradiated symmetrically within the expected design range and the reactor cores having the LTAs did not show any anomalies including fuel failure.

The fuel assembly lengths related to the compatibility with reactor internals, as well as the interference between nozzle and fuel rod, were measured and evaluated. Even though the fuel assembly length data show that the length increased after each cycle, three types of advanced fuels still had enough margins from the assembly growth point of view (see Figure 35).

The minimum top nozzle-rod gap determined by initial gap, assembly growth and rod growth should be positive during the fuel's lifetime. The evaluation results on the top nozzle-rod gap showed that there were a lot of margins after each cycle on the three types of advanced fuels.

The excessively closer gap between rods due to rod bow resulted in DNB penalty. The evaluation results of the limiting gap size after each cycle were greater than the design limit. It was evaluated that all advanced fuels had a margin from the rod-rod gap point of view.

The fuel assembly bow and twist were determined by analyzing the videotapes. The amounts of bows or twists at each cycle were within their design limits. It was concluded that all advanced fuels had the design margins from the assembly bow or twist points of view. The growth of grid width was lower than the design criterion and still had the design margin. It was, therefore, concluded that all advanced fuels had the design margins from the grid width point of view.

The fuel rod diameter is an important parameter to determine fuel performance such as pellet temperature, rod internal pressure, clad stress/strain, and rod dynamic behavior by the grid spring force change, etc. The measurement results using LVDT equipment showed that

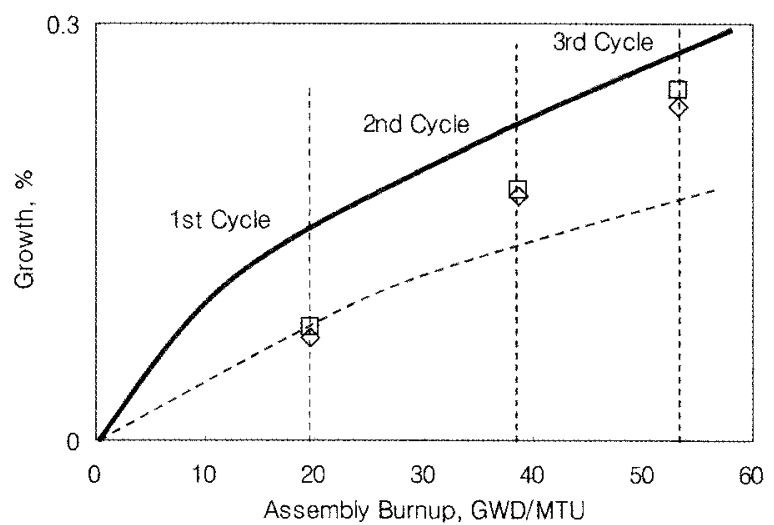

(a) PLUS7

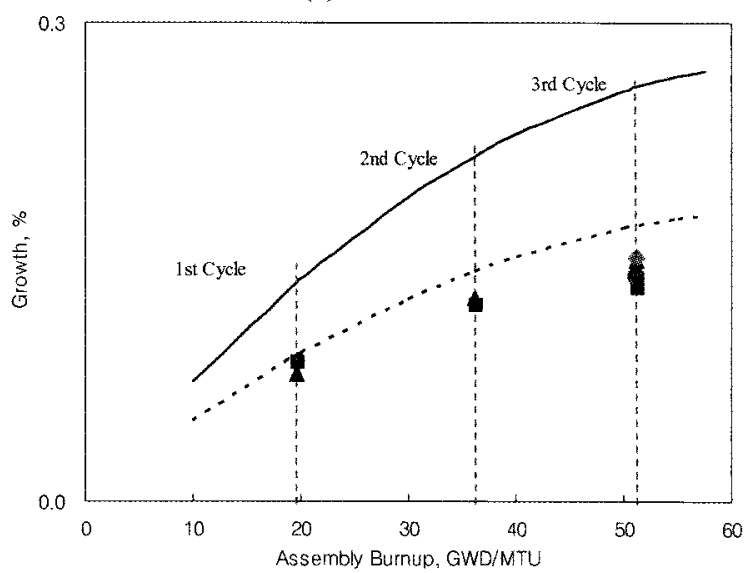

(b) $16 \mathrm{ACE} 7$

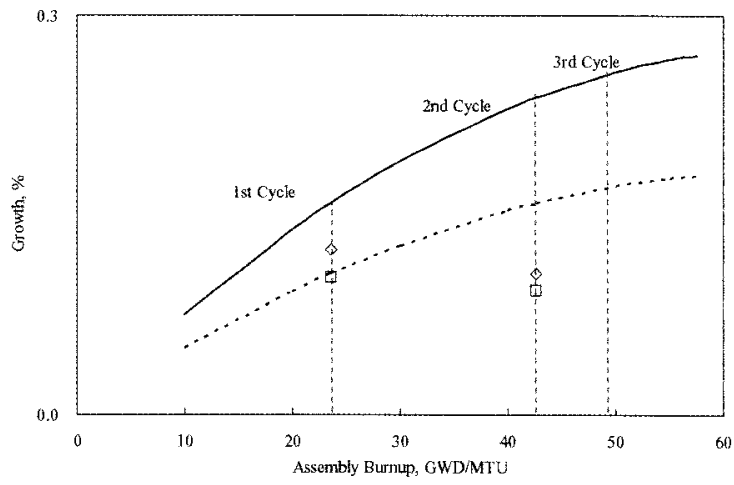

(c) 17ACE7

Fig. 35. Assembly Growth as a Function of Burnup

it had the minimum value at the higher burn-up region after the first cycle and it tended to increase after the second cycle. These tendencies were well consistent to the results expected by the design codes.

The cladding oxide layer thickness was also one of the limiting parameters to achieve high burn-up. The cladding oxide thicknesses after each cycle were measured and compared to the predicted design limits (see Figure 36). The results showed that the maximum oxide thicknesses 


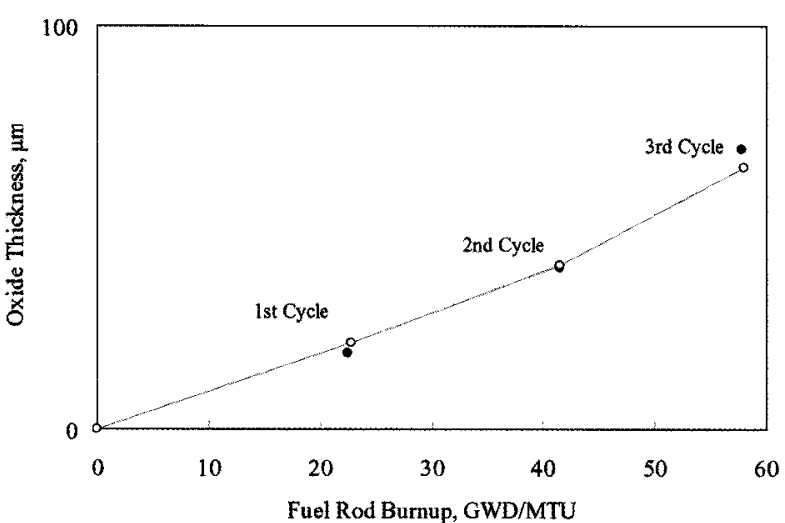

(a) PLUS7

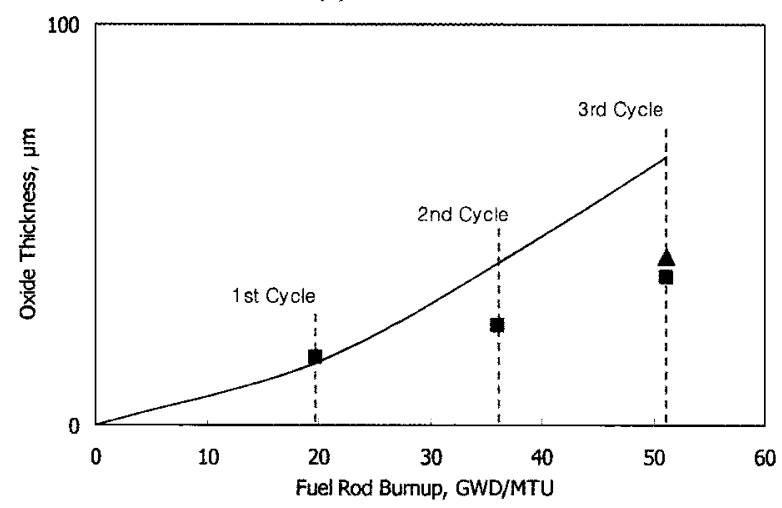

(b) 16ACE7

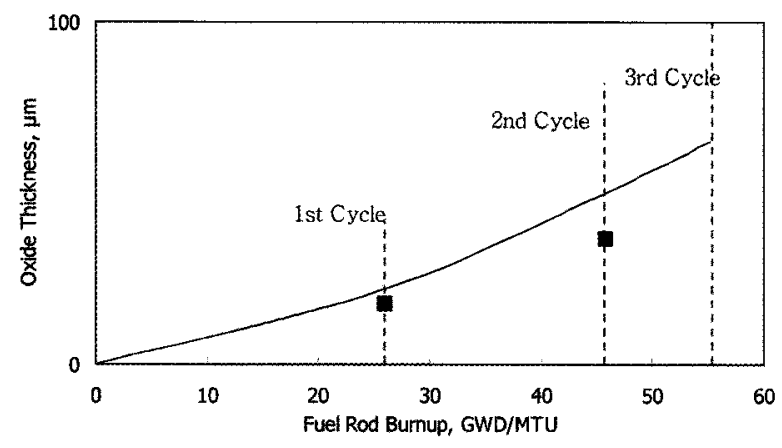

(c) 17ACE7

Fig. 36. Oxide Layer Thickness as a Function of Burnup

were within the design limits [68-70].

Rod-wise examinations were performed by disassembling two LTAs of PLUS7 and $16 \times 16$ ACE7. It was confirmed that the reconstitution of PLUS7 was easier, quicker and more convenient than that of the current fuel, and particularly $16 \times 16$ ACE7 had a reconstitution capability. From the drag force measurements, it was confirmed that the top and bottom grids were still supporting rods, even after 3 cycles of irradiations, while the mid grids were losing the spring forces little by little.

The grid-rod fretting wear performance was addressed

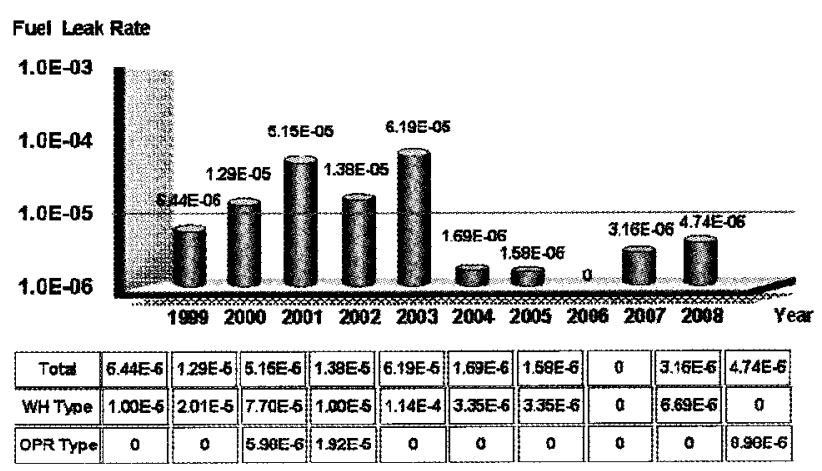

Fig. 37. Fuel Failure Rate in Korea PWR

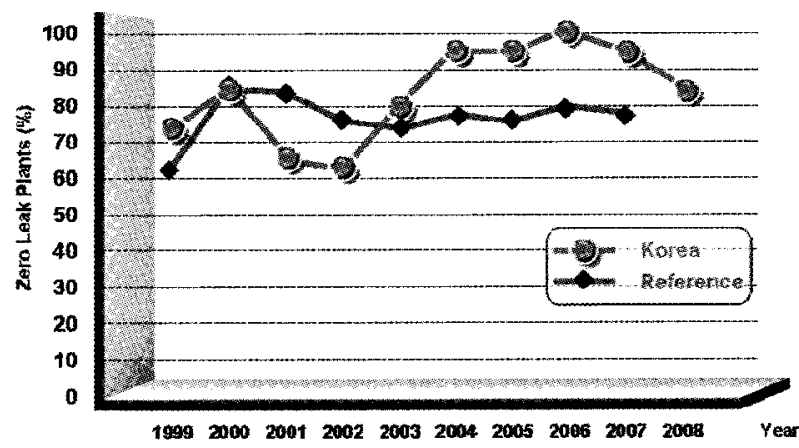

Fig. 38. Zero Leak Plants in Korea PWR

through the destructive test in hotcell during the third step of verification. It was found from hotcell tests that the marks on the fuel rod like wear scars were not wear scars but color-change due to slightly high local corrosion. Various non-destructive and destructive tests on rods in hotcell test facility were performed for PLUS7 [71].

\subsection{X-Gen Fuel development Program}

Recently KNF launched the "X-Gen Fuel Project," based on the development technologies aceumulated through the PLUS7 and ACE7 fuel developments [72]. LTAs are scheduled to be fabricated in late 2010 and inreactor verification tests using LTAs may start in 2011. Development objectives of the X-Gen Fuel can be summarized as follows:

- Burn-up: Batch average burn-up $>65 \mathrm{GWD} / \mathrm{MTU}$

- Overpower Margin: Greater than 15\% with respect to the Guardian fuel

- Seismic Performance: Meet 0.3g seismic load requirement

- Fuel Reliability: Zero defect fuel

- Manufacturability: Enhance manufacturability against the Guardian fuel 


\subsection{Operating Experiences and Fuel Performance}

As of the end of 2008, KNF has supplied PWR fuels of 4,824MTU and performed reactor core design and safety analysis for 180 reloads and 8 initial cores, providing engineering services for more operational margin and better economic efficiency of nuclear power generation such as power up-rating and relaxed axial offset control.

KNF continues to improve fuel reliability through technical upgrading of fuel design and fabrication. It results in zero defect performance achieved in 2006 and "zero leak plants" rate was recorded compared to the referenced PWR plants (see Figures 37 and 38).

\section{PHWR FUEL TECHNOLOGY}

The advanced CANDU fuel bundle, so called CANFLEX (CANDU Flexible Fuelling), had been developed jointly by KAERI and AECL[73]. It was developed to improve the safety and economics of currently operating CANDU reactors. It can provide large operating margins for existing CANDUs and allow higher burn-up by adapting the recovered uranium or slightly enrichment uranium, as well as the natural uranium as fuel material.

CANFLEX fuel has been verified through extensive testing by KAERI and AECL and has been critically reviewed under a Formal Design Review. KAERI prepared the CANFLEX-NU fuel design report for use of CANFLEX bundles in Korea and submitted it to the Korea Institute of Nuclear Safety (KINS) on July 1996 in order to obtain approval of the fuel design and fabrication method, as part of the Korean licensing process. (This approval was obtained from the Korea Ministry of Science and Technology (MOST) on August 6,1999.)

Following the government approval of the CANFLEXNU fuel design and fabrication method in Korea, as well as the successful DI (Demonstration Irradiation) of CANFLEX-NU fuel in the Point Lepreau Generating Station (PLGS), the Electric Power Research Institute (KEPRI) and KAERI jointly conducted a 3-year Industrialization Program for the use of CANFLEX-NU fuel in a CANDU 6 Wolsong Generating Station (WGS).

This paper describes the design features of CANFLEX fuel bundle and the industrialization program of CANFLEXNU fuel in Korea, covering the fuel DI in WGS-\#, the licensing documentation for the DI, and thermal-hydraulic behavior \& in-bay visual examination during the DI.

\subsection{Design Features of CANFLEX Fuel Bundle}

The CANFLEX bundle has the same bundle diameter and length as CANDU 6, 37-element natural uranium (NU) bundle, but uses 43 fuel elements. It is characterized by a moderately flat radial power profile, with the outer and intermediate rings consisting of 21 and 14 elements of $11.5 \mathrm{~mm}$ Outer Diameter (OD) and the inner ring and center rod consisting of 7 and 1 element(s) of $13.5 \mathrm{~mm}$

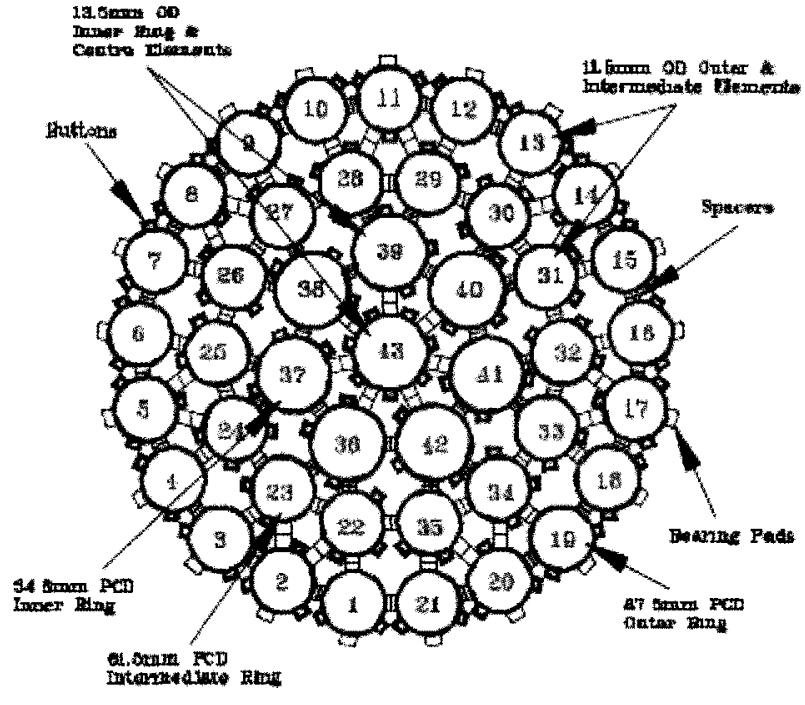

Fig. 39. CANFLEX Bundle Cross-Section

OD (Figure 39). The CANFLEX bundle assembly and its critical-heat-flux (CHF) enhancement appendages offered higher operating and safety margins than the 37-element bundle, while maintaining a full compatibility with the existing CANDU reactors.

A higher power needs to be realized before a CHF occurs, leading to a net gain in the Critical Channel Power (CCP) of at least $5 \%$ over the existing 37-element NU fuel, which is based on the results of the full scale water CHF testing of the CANFLEX bundle in the high pressure steam-water loop at the Stern Laboratories in Canada [74-76]. The greater element subdivision and the use of two element sizes lowered the peak linear-element rating, and provided a more balanced radial power distribution $[77,78]$. The maximum linear element rating in a CANFLEX bundle was $20 \%$ lower than that of a 37 -element bundle. Therefore, the bundle was well suited for the use of advanced fuel cycles, particularly those that can attain a high fuel burn-up. The higher operating and safety margins offered the potential of a reactor power up-rating, which would further increase the economic competitiveness of the CANDU reactor.

CANFLEX fuel has been designed to have similar hydraulic and neutronic characteristics to those of the existing fuel. This feature provides the operators with an ability to introduce CANFLEX bundles during normal on-power re-fuelling. No hardware changes were required to switch to CANFLEX fuel because CANFLEX fuel was fully compatible with existing fuel handling equipment [4]. Fuel channels that contained both CANFLEX and 37-element fuel during normal fuelling, have improved or unchanged operating margins. Transition to CANFLEX fuel can be gradual with no waste of existing fuel. 
In addition, CANFLEX [73] also enabled the introduction of advanced fuel cycles [77] such as Slightly Enriched Uranium (SEU), Recovered Uranium (RU) and other fuel cycles into CANDU reactors, and provided enhanced performance relative to natural uranium fuel by providing higher operating margins in existing CANDU reactors. The CANFLEX-RU offered lower fuelling costs and provided a means to raise reactor power within a fixed core size. The use of RU from PWR reactors promises to be more economical than SEU or natural uranium. The use and economics of RU are being assessed in collaborative programs with AECL and British Nuclear Fuel (BNFL).

\subsection{CANFLEX-NU Fuel Industrialization Program}

Because of the increase in critical channel power with CANFLEX, the Korea Electric Power Corporation (KEPCO) headquarter and WGS-\#1 site recognized that it could use CANFLEX to recover some of the heat transport system operation margins that was decreased due to ageing. WGS-\#1, as the first CANDU-6 nuclear power plant in Korea, has been commercially operating since April 1983. Since the late part of 1999, KEPCO has announced a program in Korea to prepare for a DI of CANFLEX-NU fuel in WGS-\#1 and potentially implement the CANFLEX-NU full core. The Korea Ministry of Science and Technology (MOST) has recognized the successful DI of 24 CANFLEX bundles at PLGS in Canada, as final verification of the CANFLEX design in preparation for full core conversion. Therefore, MOST gave financial support to a KEPRl/KAERI Joint Industrialization Program of CANFLEX-NU Fuel, which was conducted for 3 years starting in November 2000, to efficiently utilize the CANFLEX fuel technology developed by KAERI and AECL jointly, where KAERI's works have been conducted under the Korea's national program of the mid- and long-term nuclear R\&D programs since 1992.

\subsubsection{Preparation for the DI}

As part of the Korean licensing process for the design of the CANFLEX-NU bundles and the DI of 24 CANFLEX bundles in Korea, KAERI prepared a CANFLEX-NU fuel design report describing the Fuel Design (FD) and Fabrication Method (FM) and a safety assessment report for the DI in July 1996 and June 2001, respectively. The channel selection criteria for the DI in WGS-\#l were taken from those for the DI of 24 CANFLEX-NU bundles in the PLGS [79].

KEPCO Nuclear Fuel Co. Ltd. (KNFC) completed the supply of the 26 CANFLEX-NU bundles (24 fuel bundles for the DI and 2 for archival purpose) to WGS\#1 by May 2002. Also, KNFC provided the manufacturing history dockets including the manufacturing drawing (showing the specific details of manufacturing) and the product specifications. The CANFLEX fuel design was also defined by a KAERI/AECL joint reference drawing and a technical specification of the CANFLEX 43 element bundle, and all the technical specifications were also referenced from the bundle specification. The CANFLEX 4 bundles for WGS-\#1 DI had spacers of slightly higher heights in order to prevent inter-element interlocking spacers, when compared to the CANFLEX bundles used in the Point Lepreau DI. These CANFLEX bundles were manufactured at a KAERI facility by KNFC engineers in accordance with the Quality Assurance levels equivalent to the CSA Z299.2 standard normally applied to the 37element fuel supplied to WGSs.

\subsubsection{Documentation for the $D I$}

As mentioned above, on August 1999, KAERI obtained the Korean Government (MOST) approval of CANFLEXNU fuel design and fabrication method for the use of the fuel in WGSs, as part of the Korean licensing process. The major prerequisite for the DI at the WGS-\#1 was the preparation of an appropriate safety analysis for the reactor, which covers the major features of the license under which that particular reactor operates. With extensive discussions and interactions with KEPRI, KAERI had prepared the safety analysis report for the DI. With extensive discussions and interactions with WGS-\#1 site, AECL and/or KNFC, KAERI has prepared other prerequisite documents such as the operational considerations and irradiation requirements, the fuel design drawing and technical specifications, and a general guideline of the fuel manufacture, handling, and PIEs for the DI.

In the safety assessment for the DI of 24 CANFLEXNU fuel bundles at the WGS-\#1, the focus was on establishing the behaviour of CANFLEX fuel relative to the 37-element fuel. Hence, as presented in the safety assessment documents for the DI of 24 CANFLEX-NU fuel bundles at PLGS [80], these was not comprehensive re-analyses of the postulated accident scenarios, but an examination of the expected difference in accident consequences because of the 24 CANFLEX-NU fuel bundles in two channels. Even when an explicit assessment was performed, the approach was to select one or two representative cases and then to compare the relative behaviour. The accident scenarios expectantly subjected to fuel failure were selected for the safety assessment [81]: large LOCA (Loss-Of-Coolant Accident), large break LOCA with LOECC (Loss Of Emergency Core Coolant), feeder breaks, end fitting failure, flow blockage, pressure tube rupture, and so on. The CANFLEX bundle has a smaller cross-sectional area than the 37-element bundle does, thus resulting in the potential for more void to form. Therefore, the power pulse that was attributable to void of the channel may be greater in magnitude for the CANFLEX bundle relative to the 37-element fuel. The differences in power pulses between a CANFLEX channel and a 37-element channel were only a consideration for large break LOCA and loss of regulation accidents and 
had no effect on the small break LOCA analysis, pressure tube rupture analysis, flow blockage analysis, and the end fitting failure analysis. The lower maximum linear element ratings for CANFLEX bundles compared to 37 element bundles at the same bundle power led to that any adverse consequences with the CANFLEX bundles for the accident scenarios that were not expected to result in any fuel failure, and therefore, the postulated accidents such as small break LOCA, loss of Class IV power, loss of HTS pumps in the primary circuit, loss of feed-water, steam-line breaks, and so on were not analyzed for this safety assessment. In the single channel analyses for the explicit assessments, behaviour for an all-37-element channel was compared to that for an all-CANFLEX channel. For mixed strings, the impact on key safety results would be intermediate between these two cases, due to the very similar behaviour thermal-hydraulic and neutronic behaviour of the two bundle types. Explicit assessments used the computer codes and analysis methods which were employed in the safety analyses for the WGS2, 3, and 4 Final Safety Report [82], because computer programs had been used for the WGS-\#I Safety Report [83] were not available or had been upgraded at that time and also the analysis methods and assumptions had been updated. When individual channels were considered, channel 006 with a channel power of $7.3 \mathrm{MW}$ and a peak bundle power of $935 \mathrm{~kW}$ was the basis of the simulations.

\subsubsection{Thermal-hydraulic Behavior of the CANFLEX During the DI}

The fuelling of the 24 CANFLEX fuel bundles into two separate fuel channels of WGS-\#1 was planned in order to maintain a minimum risk and maximum flexibility of the reactor operation. One was a high power channel, Q07, near the mid-level of the Liquid Zone Controllers and two regular eight-bundle shift fuellings of a CANFLEX fuel. The other was a low power channel, L21, and would receive one eight-bundle shift fuelling of a CANFLEX fuel. The net duration of the DI was 16 months from the period of July 10, 2002 to January 29, 2004, where a period of the reactor's planned outage from January 31 to March 16, 2003 during the DI was not included.

In order to track the core during the DI, the reactor operation data such as the inlet and outlet header pressures and temperatures, the CANFLEX fuel channel pressures and temperatures, and others were obtained from WGS\#1, where the data was measured every day, and every minute for the fuelling periods of the CANFLEX or 37element fuel bundles into the Q07 and L21 channels. The WGS-\#1 operated to a $100 \%$ reactor full power during the DI. The daily data of the reactor operation during the DI was recorded and presented in detail at the 8th International CNS CANDU Fuel Conference Proceedings [84]. As an example, the outlet temperatures of the Q07 and L21 channels during the DI period between July 11, 2002 and April 21, 2003 were $308.183 \pm 0.237^{\circ} \mathrm{C}$ and 306.510
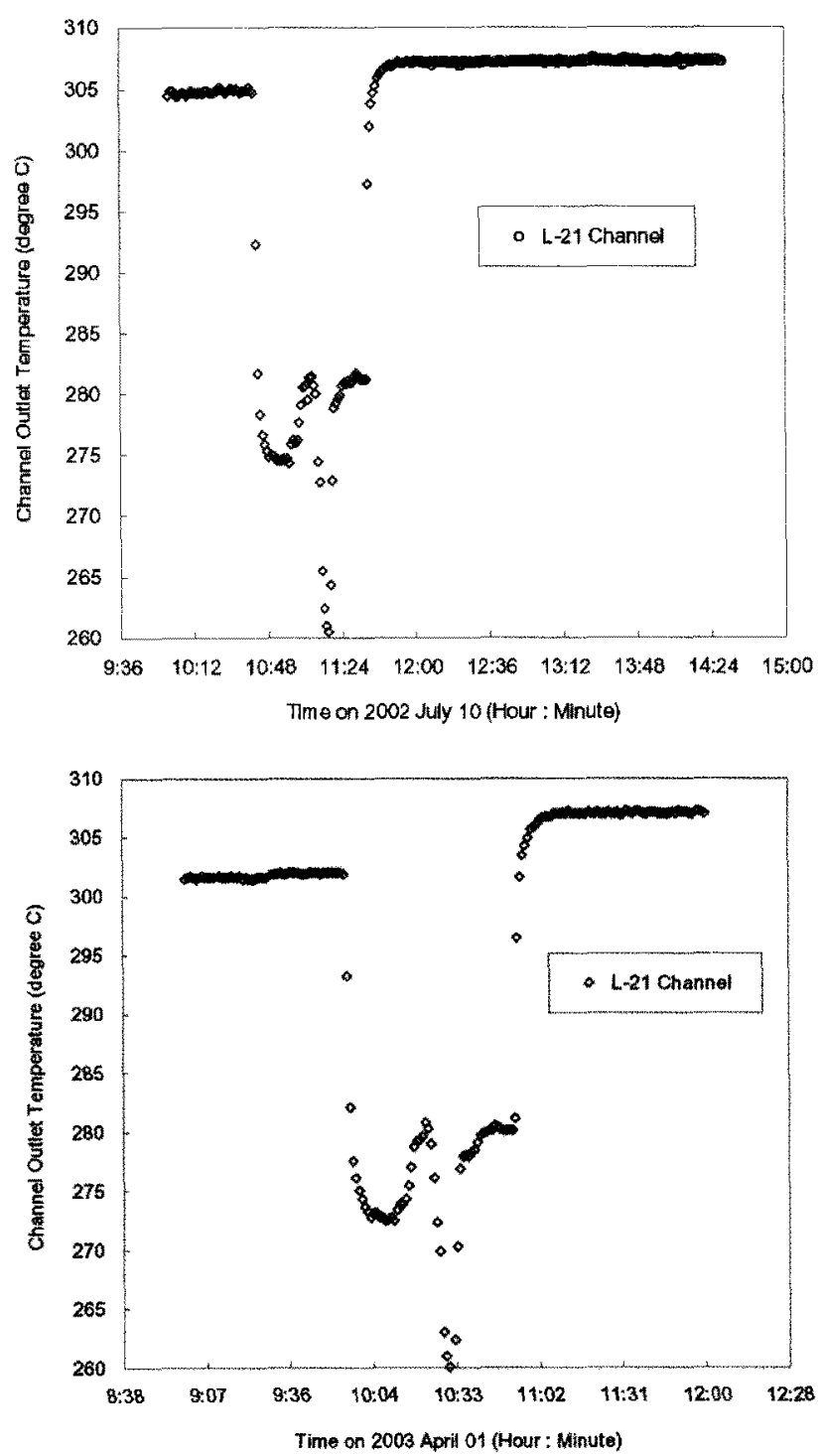

Fig. 40. L21 Channel Outlet Coolant Temperature Data during the Fuellings on 2002 July 10 and 2003 April 01

$\pm 0.850^{\circ} \mathrm{C}$, respectively. The channel flow rates of the Q07 and L21 channels for the DI period from September 25,2002 to January 29,2004 were $26.57 \pm 0.92 \mathrm{~kg} / \mathrm{s}$ and $20.04 \pm 0.16 \mathrm{~kg} / \mathrm{s}$, respectively.

Figures 40 and 41 show the outlet temperature variations of the Q07 and L21 channels for their fuelling periods, which are not different from those of the channels with 37-element NU fuel bundle's fuelling periods. As expected, the outlet temperature change of the low power channel L21 was quite sensitive to the fuelling operation, in comparison with that of the high power channel Q07. The average temperatures of the Q07 high power channel outlet were $\sim 2$ to $3{ }^{\circ} \mathrm{C}$ higher than those of the low power 

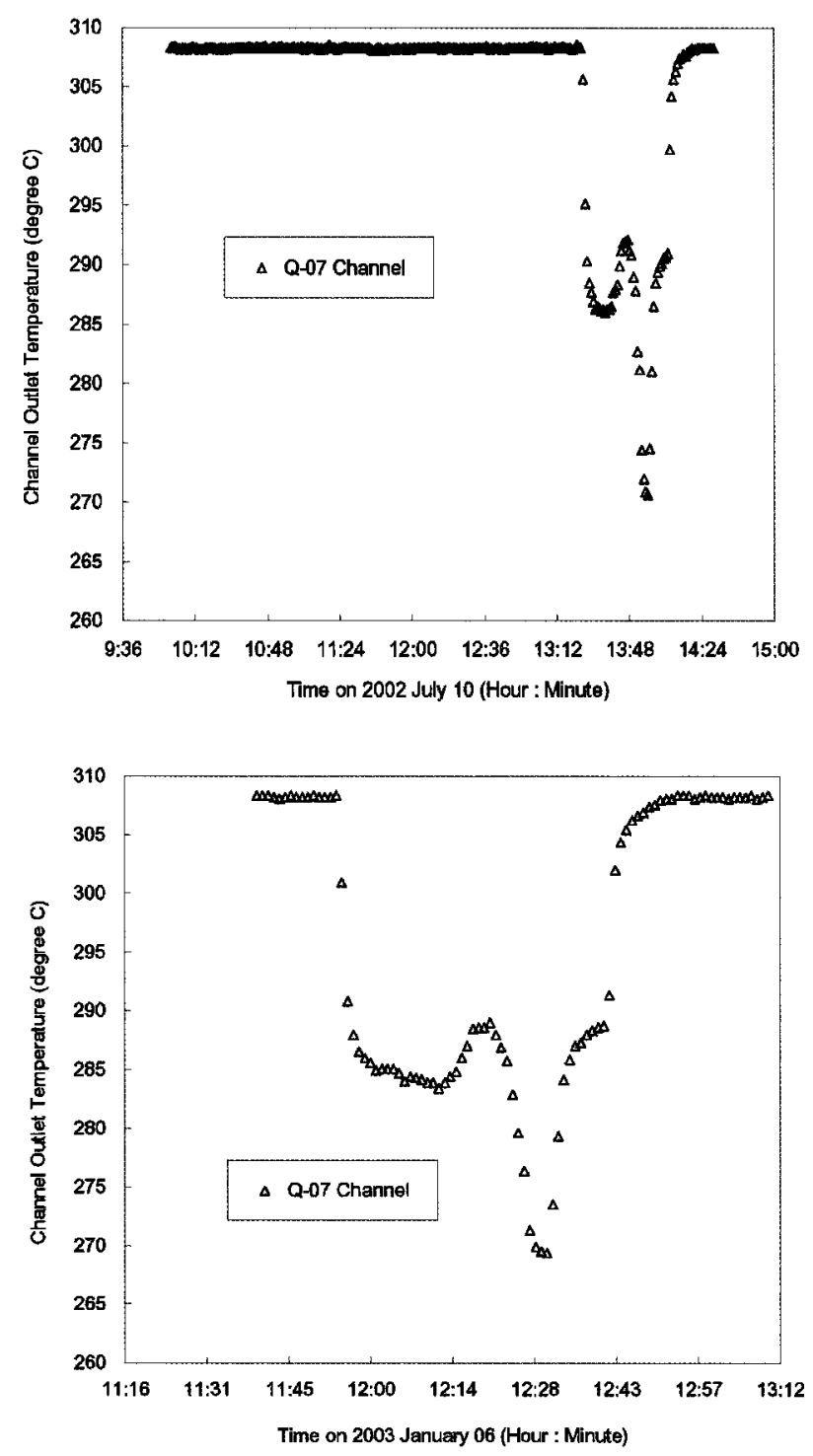

Fig. 41. Q07 Channel Outlet Coolant Temperature Data during the Fuellings on 2002 July 10 and 2003 January 06

channel L21. The small variation in the daily reactor normal operation data indicates that the reactor was stably operating during the DI.

\subsubsection{In-Bay Visual Examinations of the Irradiated CANFLEX-NU Fuel}

In November 2003, at WGS-\#1 irradiated fuel storage, the in-bay visual examinations on the 4 bundles discharged from the Q07 channel and the 1 bundle discharged from the L21 channel were conducted by KAEIR and KEPRI staffs and an AECL expert. As shown in Figures 42 and 43, the examinations focused on observations of a side stop interaction, refuelling impact, cross flow fatigue/fretting,

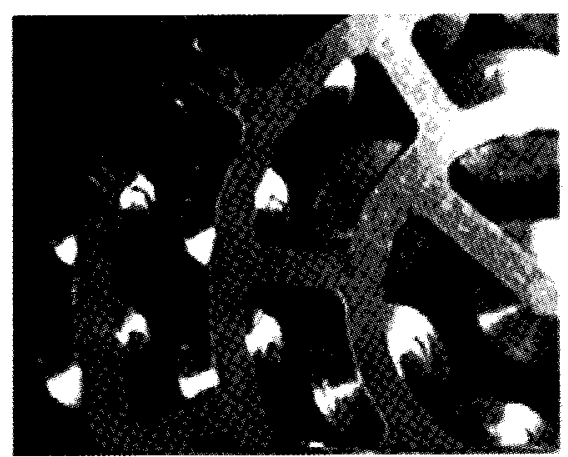

Fig. 42. CANFLEX-NU KF0119 Bundle-Serial

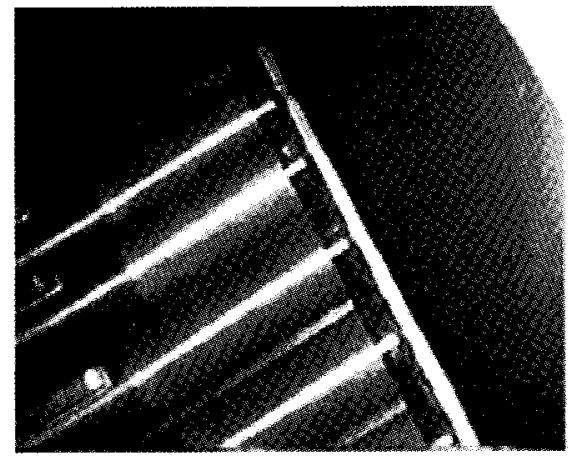

Fig. 43. CANFLEX-NU KF0119 Bundle - Endcaps-Endplate Welding

spacer fretting of a non-outer element, a fuel element bow and longitudinal ridge, appendage wear and crevice corrosion, weld points, sheath oxidation, and an endplate integrity. As for the examination results, it was concluded that all the bundles were intact, free of defects and appeared to be in good condition as expected.

\section{CONCLUSIONS}

The PWR fuel R\&D in KAERI has produced many significant results and achievements during the period from 1997 to 2006. These technologies are self-reliant and have been upgraded to a global level. New cladding tubes have been developed which have a high corrosion resistance and a high creep strength. Related technologies were also secured such as an alloy design, heat-treatment, and out-of-pile / in-reactor tests. A new sintering process was developed for the fabrication of large grain $\mathrm{UO}_{2}$ pellets. Uranium oxide seeds and aluminum oxide were involved in this process as a grain growth promoter. A fuel performance analysis code was developed which can accurately deal with high burnup effects such as a rim 
structure formation and a fission gas release. A spacer grid was developed which can be characterized as a thetashape spring and a hybrid -mixing vane. Owing to these features, a rod-supporting ability and a thermal margin improved significantly. Test facilities were also constructed for mechanical and thermal hydraulic tests of a full size fuel assembly.

KAERI has been developing a basic LWR MOX technology for fuel pellet fabrication and fuel performance analysis code, COSMOS. Two test MOX fuel rods manufactured through international cooperation were irradiated in the Halden reactor up to about $50 \mathrm{MWd} / \mathrm{kgHM}$. Real time in-reactor data showed that COSMOS can predict the in-pile behavior of MOX fuel reasonably up to high burn-up. Furthermore, PIE of the irradiated fuel also showed that microstructures of the KAERI's two fuel rods were comparable to those of the BNFL one. In summary, it can be concluded that the basic LWR MOX technology of KAERI has proved to be very satisfactory

KNF has been supplying nuclear fuel and related engineering services including safety analysis for all nuclear power plants in Korea since 1989. The commercial nuclear fuel technologies have been developed by a stepby-step strategic approach. KNF established the nuclear fuel technologies, based on technologies transferred from foreign fuel vendors, and then KNF has continued to focus on developing PWR fuels that will meet the challenge of increasing fuel duty requirements in Korea. Through these programs, KNF has successfully developed three types of advanced fuels that include PLUS7 for the OPR 1000 s and the APR1400s, the $16 \times 16$ ACE7 for 2-loop Westinghouse type plant and $17 \times 17$ ACE7 for the 3-loop Westinghouse type plants. In addition, KNF launched the "X-Gen Fuel Project" in 2005 and plans to complete it by 2011 .

CANFLEX fuel had been under development for over 10 years through collaboration between Canada and Korea. Following the successful approval of the CANFLEXNU design and fabrication method by the Korean Government as well as the successful DI of CANFLEXNU fuel in PLGS, a KEPRI/KAERI CANFLEX-NU Joint Industrialization Program started in November 2000 to cover a DI of 24 CANFLEX-NU fuel bundles in WGS$\# 1$ and the safety analyses for the full-core conversion of the fuel in the reactor. It was concluded that the DI shows the validation of the CANFLEX bundle performance with direct conditions of relevance under the Korean licensing requirements and the CANFLEX fabrication capability, and provides the rationale for the decision to perform the full-conversion of a CANFLEX fuel in Wolsong \#1.

\section{ACKNOWLEDGEMENT}

The authors would like to thank the colleagues, Dr. J.Y. Park, Dr. K.S. Kim, Dr. J.G. Bang, Dr. T.H. Chun, Dr. H.K. Kim, and Dr. H.T. Kim of KAERI and Mr. J.I. Kim, Mr. Y.H. Kim, and Mr. J.M. Suh of KNF, for their contributions.

\section{REFERENCES}

[1] K.W. Song, Y.H. Jeong, K.S. Kim, J.G. Bang, T.H. Chun, H.K. Kim, and K.N. Song, "High Burnup Fuel Technology in Korea," Nucl. Eng. \& Tech., 40, 21 (2008).

[2] J.Y. Park, S.J. Yoo, B.K. Choi, and Y.H. Jeong, "Oxide Microstructures of Advanced $\mathrm{Zr}$ Alloys Corroded in $360^{\circ} \mathrm{C}$ Water Loop," J. Alloys and Compounds, 437, 274 (2007).

[3] J.Y. Park, B.K. Choi, S.J. Yoo, and Y.H. Jeong, "Corrosion and Oxide Properties of HANA alloys," J. ASTM Int., 5, 5, Paper ID JAI101129.

[4] Y.H. Jeong, K.O. Lee, and H.G. Kim, "Correlation between Microstructure and Corrosion Behavior of $\mathrm{Zr}-\mathrm{Nb}$ Binary Alloys," J. Nucl. Mater., 302, 9 (2002).

[5] J.Y. Park, B.K. Choi, Y.H. Jeong, and Y.H. Jung, "Corrosion Behavior of Zr Alloys with a High Nb Content," J. Nucl. Mater., 340, 237 (2005).

[6] H.G. Kim, J.Y. Park, and Y.H. Jeong, "Phase Boundary of the Zr-rich Region in Commercial Grade Zr-Nb Alloys," J. Nucl. Mater., 347, 140 (2005).

[7] V.F. Urbanic, B.D. Warr, A. Manolescu, C.K. Chow, and M.W. Shanahan, "Oxidation and Deuterium Uptake of Zr$2.5 \mathrm{Nb}$ Pressure Tube in CANDU-PHW Reactors," Zirconium in the Nuclear Industry, ASTM STP 1023, p.20 (1989).

[8] V.F. Urbanic, R.W. Gilbert, "Effect of Microstructure on the Corrosion of $\mathrm{Zr}-2.5 \% \mathrm{Nb}$ Alloys," Proc. of IAEA Technical Committee Meeting on Fundamental Aspects of Corrosion on Zirconium Based Alloys in Water Reactor Environments (IWGFPT/34), IAEA, Vienna, Italy, p.262 (1990).

[9] J.H. Kim, M.H. Lee, B. K. Choi, Y.H. Jeong, "Deformation and Thermal Quench Behavior of HANA Cladding in LOCA Condition," Proc. of 2005 Water Reactor Fuel Performance Meeting, Kyoto, Japan, Oct. 2-6 (2005).

[10] J.H. Baek, Y.H. Jeong, "Breakaway Phenomenon of ZrBased Alloys During a High-temperature Oxidation," $J$. Nucl. Mater., 372, 152 (2008).

[11] H. Assmann and H. Bairiot, "Process and Product Control of Oxide Powder and Pellets for Reactor Fuel Application", Guidebook on Quality Control of Water Reactor Fuel, Tech. Report Series No. 221, IAEA, Vienna (1983).

[12] J.A. Turnbull, "The Effect of Grain Size on the Swelling and Gas Release Properties of $\mathrm{UO}_{2}$ During Irradiation," $J$. Nucl. Mater., 50,62 (1974).

[13] Y. Harada, "Sintering Behaviour of Niobia-doped Large Grain $\mathrm{UO}_{2}$ Pellet," J. Nucl. Mater., 238, 237 (1997).

[14] K.W. Song, K.S. Kim, K.W. Kang, and Y. H. Jung, "Effect on $\mathrm{Nb}_{2} \mathrm{O}_{5}$ and Oxygen Potential on Sintering Behavior of $\mathrm{UO}_{2}$ Fuel Pellets," J. Korean Nucl. Soc., 31, 335 (1999).

[15] J.B. Ainscough, F. Rigby, and S.C. Osborn, "The Effect of Titania on Grain Growth and Densification of Sintered $\mathrm{UO}_{2}, "$ J. Nucl. Mater., 52, 191 (1974).

[16] L. Bourgeois, Ph. Dehaudt, C. Lemaignam, and A. Hamnou, "Factors Governing Microstructure Development of $\mathrm{Cr}_{2} \mathrm{O}_{3}$, Doped $\mathrm{UO}_{2}$ during Sintering," J. Nucl. Mater., 297, 313 (2001).

[17] B.E. Ingleby and K. Hand, Fission-Product Behavior in Ceramic Oxide Fuel, Advances in Ceramics, vol. 17, I.J. Hastings (eds), p.57, Amer. Ceramic Soc.(1986).

[18] Y. Harada and S. Doi, "Irradiation on Behavior of Large Grain $\mathrm{UO}_{2}$ Fuel Rod by Active Powder," J. Nucl. Sci. 
Technol., 35, 411 (1998).

[19] G.A. Wood and C.P. Perkins, "Advances in Pellet Technology for Improved Performance at High Burnup," IAEA-TECDOC-1036, IAEA, Vienna, p. 49 (1998).

[20] K.W. Song, K.S. Kim, K.W. Kang, and Y.H. Jung, "Grain Size Control of $\mathrm{UO}_{2}$ Pellets by Adding Heat-treated $\mathrm{U}_{3} \mathrm{O}_{8}$ Particles to $\mathrm{UO}_{2}$ Powder," J. Nucl. Mater., 317, 204 (2003).

[21] Jae Ho Yang, Kun Woo. Song, Keon Sik Kim, and Youn Ho. Jung, "A Fabrication Technique for a $\mathrm{UO}_{2}$ Pellet Consisting of $\mathrm{UO}_{2}$ Grains and a Continuous W Channel on the Grain Boundary," J. Nucl. Mater., 353, 202 (2006).

[22] C.B. Lee, Y.S. Yang, Y.M. Kim, D.H. Kim, J.G. Bang, and Y.H. Jung, "High Burnup $\mathrm{UO}_{2}$ Fuel Rod Performance Code INFRA," Proc. of the 2004 International Meeting on LWR Fuel Performance, Orlando, Florida, Sep. 19-22, 2004.

[23] C.B. Lee and Y.S. Yang, "INFRA Code Results of FUMEX-II," IAEA CRP Improvement of models used for fuel behavior simulation (FUMEX-II), IAEA, Vienna, Dec. 5-8, 2005.

[24] S. Ravel, et al., "Partitoning of Grain Boundary and Matrix Gas Inventories: Results Obtained Using the ADAGIO Facility," Fission Gas Behavior in Water Reactor Fuels, Cadarache, France, 2002.

[25] D. H. Kim et al., "Post-Irradiation Annealing Test of High Burnup $\mathrm{UO}_{2}$ Fuel", 2005 Water Reactor Fuel Performance Meeting, Kyoto, Japan, Oct. 2-6, 2005.

[26] Averty, X. et. al., "Tensile Tests on Ring Specimens Machined in M5 Cladding Irradiated 6 Cycles," IRSN 2003/50(2003).

[27] D. O. Hobson et al., "Embrittlement of Zircaloy Clad Fuel Rods by Steam during LOCA Transients," ORNL-4758(1972).

[28] H.-K. Kim, Y.-H. Lee, and Y.-H. Jung, "Development of High Temperature \& Pressure Fuel Rod Fretting Wear Tester," Transactions of the KSTLE spring meeting, Korea, 2003.

[29] T.M. Frick, T.E. Sobek, and J.R. Reavis, "Overview on the Development and Implement of Methodologies to Compute Vibration and Wear of Steam Generator Tubes," Symposium on Flow Induced Vibration: Vol. 3, Vibration in Heat Exchanger, p. 149 (1984)

[30] Y.-H. Lee and H.-K. Kim, "Effect of Spring Shapes on the Variation of Loading Conditions and the Wear Behaviour of the Nuclear Fuel Rod During Fretting Wear Tests," Wear, 263, 451 (2007).

[31] Y.-H. Lee and H.-K. Kim, "A Study on the Fretting Wear Resistance of a Zirconium Alloy with the Variation of Supporting Spring Properties," Key engineering materials, 345-346, 1365 (2007).

[32] H.-K. Kim, Y.-H. Lee, and K.-H. Lee, "On the Geometry of the Fuel Rod Supports Concerning a Fretting Wear Failure," Nucl. Eng. Design, 238, 3321 (2008).

[33] H.-S. Kang, K.-H. Yoon, K.-N. Song, and Y.-H. Jung, "Development of the Flow-induced Vibration Loop for a 5x5 Partial Fuel Assembly," Transactions of the Korean Nuclear Society Autumn Meeting, Oct. 25-26, 2002.

[34] K.-H. Lee, K.-H. Yoon, K.-N. Song, and J.-Y. Kim, "Comparative Study on Flow-Induced Vibration of a $5 \times 5$ partial Fuel Assembly for Design Verification of the Newly Developed Spacer Grids," Transactions of the Korean Nuclear Society Spring Meeting, May 25-26, 2006.

[35] K.-H. Lee, J.-Y. Kim, K.-H. Yoon, and K.-N. Song, "High
Frequency Flow-Induced Vibration of the $5 \times 5$ Test Bundle," Transactions of the Korean Nuclear Society Autumn Meeting, Nov. 2-3, 2006.

[36] K.-H. Lee, K.-H. Yoon, J.-Y. Kim, K.-N. Song, and D.-S. Oh, "Orbital Vibratory Motion of a Fuel Rod in a $5 \times 5$ Partial Fuel Assembly in a Confined Axial Flow," ICAPP'07, France, May 15-19, 2007.

[37] K.H. Yoon, H.S. Kang, H.K. Kim, K.N. Song, and Y.H. Jung, "Pendulum Type Impact Test on the Partial Spacer Grid under Room and Operation Temperature Conditions," KNS Spring Conference, 2002 (in Korean).

[38] K.H. Yoon, K.H. Lee, and K.N. Song, "Buckling Behavior as the Configuration of a Grid Assembly under the Lateral Impact Load," KSME Spring Conference, 2006(in Korean).

[39] K.H. Yoon, W.K In, H.S. Kang, and K.N Song, "Developed Spacer Grid for Future PWR Fuel Assembly Considered Thermal/Hydraulic and Mechanical/Structural Performance," ICONE-12, 2004

[40] K.N. Song, K.H. Yoon, J.Y. Kim, and K.H. Lee, "Multydisplinary Design of the Spacer Grid Assembly for PWR," IWMDE2006, Japan, 2006.

[41] H.-K. Kim and S.-J. Kim, "Development of Algorithm for Wear Volume Evaluation using Surface Profile Analysis," J. Kor. Soc. Tribologists and Lubr. Engrs., 17, 33 (2001).

[42] W.K. In, "Numerical Study of Coolant Mixing caused by the Flow Deflectors in a Nuclear Fuel Bundle," Nuclear Technology, 134, 187 (2001).

[43] W.K. In, T.H. Chun, and C.H Shin, "Numerical Computation of Heat Transfer Enhancement of a PWR Rod Bundle with Mixing Vane Spacers," Nuclear Technology, 161, 69 (2008).

[44] D.S. Oh, W.K. In, and T.H. Chun, "Structure of Turbulent Flow in Subchannel of Rod Bundle Downstream of Spacer Grid with Hybrid Flow Mixing Device," ICONE-10, 2002.

[45] D.S. Oh, S.K. Chang, B.D. Kim, S.Y. Chun, T.H. Chun, "Pressure Drop Test of Hybrid Mixing Vane Spacer Grid," KAERI/TR-3441/2007, Korea Atomic Energy Research Institute (2007).

[46] C.H. Shin, Y.J. Choo, S.K. Moon, S.Y. Chun, T.H. Chun, "CHF Performance of Hybrid Mixing Vane Grid for a Nuclear Fuel Bundle," Int. LWR Fuel Performance Meeting, San Francisco, 2007.

[47] K.-H. Lee, et al., "Vibration Characteristics of the Grid Cage Assembly," Transactions of the Korean Nuclear Society Autumn meeting, Oct. 27-28, 2005.

[48] K.-H. Lee, et al., "Lateral Vibration Characteristic Test of $16 \times 16$ PWR Fuel Assembly," KSME Annual Spring Meeting, June 7-9, 2006 (in Korean).

[49] Han Soo Kim, Chang Yong Joung, Byung Ho Lee, Jae Yong Oh, Yang Hyun Koo, and Peter Heimgartner, "Applicability of $\mathrm{CeO} 2$ as a Surrogate for $\mathrm{PuO}_{2}$ in a MOX Fuel Development," J. Nucl. Mater., 98, 378 (2008).

[50] Chang Young Joung, Soo Chul Lee, Si Hyung Kim, Han Soo Kim, and Dong-Seong Sohn, "Fabrication Method for $\mathrm{UO}_{2}$ Pellets with Large Grains or a Single Grain by Sintering in Air," J. Nucl. Mater., 209, 375 (2008).

[51] Christian Hellwig, Uwe Kasemeyer, Guido Ledergerber, Byung-Ho Lee, Young-Woo Lee, and Rakesh Chawla, "Interpretation of Experimental Results from ModeratePower In-pile Testing of a Pu-Er-Zr-oxide Inert Matrix Fuel," Annals of Nuclear Energy, 287, 30 (2003).

[52] Yang-Hyun Koo, Byung-Ho Lee, and Dong-Seong Sohn, 
"COSMOS: A Computer Code to Analyze LWR $\mathrm{UO}_{2}$ and MOX Fuel up to High Burnup," Annals of Nuclear Energy, 47, 26 (1999).

[53] Yang-Hyun Koo, Byung-Ho Lee, and Dong-Seong Sohn, "Analysis of Fission Gas Release and Gaseous Swelling in $\mathrm{UO}_{2}$ Fuel Under the Effect of External Restraint," $J$. Nucl. Mater, 86, 280 (2000).

[54] Yang-Hyun Koo, Byung-Ho Lee, Jin-Sik Cheon, and DongSeong Sohn, "Modeling and Parametric Studies of the Effect of Inhomogeneity on Fission Gas Release in LWR MOX Fuel," Annals of Nuclear Energy, 271, 29 (2002).

[55] Byung-Ho Lee, Yang-Hyun Koo, Jin-Sik Cheon, Je-Yong Oh, and Dong-Seong Sohn, "A Unified Thermal Conductivity Model for LWR MOX Fuel Considering Its Microstructural Characteristics," Actinides 2001, Hayama, Japan, 2001.

[56] H. Kampf and G. Karsten, "Effects of different types of void volumes on the radial temperature distribution of fuel pins," Nucl Tech., 9, 288 (1970).

[57] Byung-Ho Lee, Yang-Hyun Koo, Je-Yong Oh, and DongSeong Sohn, "Zircaloy-4 Cladding Corrosion Model Covering a Wide Range of PWR Experiences," J. Nucl. Mater., 127, 378 (2008).

[58] Byung-Ho Lee, Yang-Hyun Koo, Jin-Sik Cheon, and Dong-Seong Sohn, "Modeling of Creep Behavior of Zircaloy 4 by Considering Metallurgical Effect," Annals of Nuclear Energy, 1, 29 (2002).

[59] Yang-Hyun Koo, Byung-Ho Lee, Jin-Sik Cheon, and Dong-Seong Sohn, "Pore Pressure and Swelling in the Rim Region of LWR High Burnup $\mathrm{UO}_{2}$ Fuel," J. Nucl. Mater., 213, 295 (2001).

[60] Byung-Ho Lee, Yang-Hyun Koo, Je-Yong Oh, Jin-Sik Cheon, and Dong-Seong Sohn, "Improvement of Fuel Performance Code COSMOS with Recent In-pile Data for MOX and $\mathrm{UO}_{2}$ Fuels," Nucl. Tech., 53, 157 (2007).

[61] Wolfgang Wiesenack, Byung-Ho Lee, and Dong-Seong Sohn, "Irradiation Test of MOX Fuel in the Halden Reactor and the Analysis of Measured Data with the Fuel Performance Code COSMOS," Nuclear Engineering and Technology, 317, 37 (2005).

[62] Byung-Ho Lee, Yang-Hyun Koo, and Dong-Seong Sohn, "Irradiation test of MOX fuel in the Halden reactor up to $50 \mathrm{MWd} / \mathrm{kgHM}, "$ KNS Spring Meeting, May, 2007.

[63] K.T. Kim, Y.H. Kim, Y.K. Jang, and D.L. Stucker, "PLUS 7 Advanced Fuel Development for the CE 16x16 type Nuclear Power Plants," 13th Pacific Basin Nuclear Conference, China, Oct., 2002.

[64] S.J. King, K.L. Jeon, R.P. Knott, S.Y. Jeon, M.E. Dye, and R. Esteves, "Advanced PWR Fuel Assembly Development Programs in Korea," 18th KAIF/KNS Annual Conference, Seoul, Korea, Apr. 9-11, 2003.

[65] K.L. Jeon, S.Y. Jeon, K.T. Kim, D.H. Kang, D.S. Suh, M. Boone, S.J. King, R.P. Knott, J.L. Norrell, and R. Esteves, "Updated Status of Advanced $16 \times 16$ and $17 \times 17$ Fuel Assembly Developments in Korea," 19th KAIF/KNS Annual Conference, Seoul, Korea, Apr. 25-27, 2004

[66] K.T. Kim and J.M. Suh, "Development of an Advanced PWR Fuel for OPR1000s in Korea," Nuclear Engineering and Design, 238, 2606 (2008).

[67] J.I. Kim, J.C. Shin, Y.K. Jang, K.L. Jeon, Y.B. Chun, S.B. Ahn, W.S. Ryu, P.W. Moon, T.K. Choe, "Irradiated Fuel Examination Program in Korea," The 23rd KAIF/KNS
Annual Conference, Seoul, Korea, Apr. 16-18, 2008.

[68] K.T. Kim, Y.K. Jang, and J.I. Kim, "In-Reactor Performance of an Advanced PWR Fuel, PLUS7, for OPR 1000 in Korea," J. of Nuclear Science and Technology, 45, 836 (2008).

[69] Y.K. Jang, K.L. Jeon, K.T. Kim, J.I. Kim, and J.Y. Park, "Irradiation Performances of Korean Advanced Fuels for Nuclear Power Plants," 16th Pacific Basin Nuclear Conference, Aomori, Japan, Oct. 13-18, 2008.

[70] Y.K. Jang, K. L. Jeon, J. I. Kim, Y. H. Kim, and J. Y. Park, "In-Reactor Performance of Advanced Fuel 16ACE7TM, for Kori 2 Nuclear Power Plant," 2008 Water Reactor Fuel Performance Meeting, Seoul, Korea, Oct. 19-23, 2008.

[71] J.I. Kim, J.C. Shin, Y.K. Jang, K.L. Jeon, Y.B. Chun, P.W. Moon, and T.K. Choe, "Irradiated Fuel Examination Program for Advanced PWR Fuels in Korea," Proceedings of 2008 KAERI/JAEA Joint Seminar on Advanced Irradiation and PIE Technology, Daejeon, Korea, Nov. 5-7, 2008.

[72] K.T. Kim, J.H. Choi, J.M. Suh, "Strategy of Advanced PWR Fuel Development in Korea," Proc. European Nuclear Society, Brussels, Belgium, Sep.16-20, 2007.

[73] H.C. Suk, K-S. Sim, B.G. Kim, C. B. Choi, C. H. Chung, A. D. Lane, D. F. Sears, J. H. K. Lau, I. Oldaker, and P. G. Boezar, "CANFLEX as a CANDU Advanced Fuel Bundle," Proceedings of the 5th International Topical Meeting on Nuclear Thermal Hydraulics, Operations and Safety, p.UI1, Beijing, China, Apr., 1997.

[74] G.R. Dimmick, W.W. Inch, J.S. Jun, H.C. Suk, G.I. Hadaller, R.A. Fortman, and R.C. Hayes, "Full Scale Water CHF Testing of the CANFLEX Bundle," Proceedings of the 6 th International Conference on CANDU Fuel, Vol. 2, Niagara Falls, Ontario, Canada, Sep. 26-30, 1999.

[75] L.K.H. Leung, D.C. Groeneveld, G.R. Dimmick, D.E. Bullock, and W.W. Inch, "Critical Heat Flux and Pressure Drop for a CANFLEX Bundle String Inside an Axially Non-Uniform Flow Channel," Proceedings of the 6th International Conference on CANDU Fuel, Vol. 1, Niagara Falls, Ontario, Canada, Sep. 26-30, 1999.

[76] L.K.H. Leung, J.S. Jun, G.R. Dimmick, D.E. Bullock, W.W. Inch, and H.C. Suk, "Dryout Power of a CANFLEX Bundle String with Raised Bearing," Proceedings of the 7th International Conference on CANDU Fuel, Vol. 1, p.27, Kingston, Ontario, Canada, Sep. 23-27, 2001.

[77] H.C. Suk, K-S. Sim, B.G. Kim, C.B. Choi, C.H. Chung, A.D. Lane, D.F. Sears, J. H.K. Lau, I. Oldaker, and P.G. Boczar, "CANFLEX as a CANDU Advanced Fuel Bundle," Proceedings of the 5th International Topical Meeting on Nuclear Thermal Hydraulics, Operations and Safety, p.U1-1, Beijing, China, Apr., 1997.

[78] A.D. Lane, G.R. Dimmick, J.H. K. Lau, H.C. Suk, C.H. Chung, and C.B. Choi, "CANFLEX : A New CANDU Fuel Bundle with Expended Operating Capabilities," Proceeding of the 11th KAIF/KNS Annual Conference, Seoul, Korea, Apr. 11-12, 1996.

[79] Wayne W.R. Inch, Paul D. Thompson, Patrick J. Reid, and Ho Chun Suk, "Demonstration Irradiation of CANFLEX in CANDU 6 Power Reactor," Proceedings of 14 th KAIF/KNS Annual Conference, Seoul, Korea, Apr. 18-20, 2001.

[80] Z. Bilanovic et. al, "Safety Assessment for the 24 CANFLEX Bundle Demonstration Irradiation at Point Lepreau Generating Station," AECL Report TTR-636, Vol. 1-9 (1998). 
[81] H.S. Lim and H.C. Suk, "Safety Assessment for the CANFLEX-NU Fuel Bundles with respect to the 37-ElJement Fuel Bundles," KAERI/TR-1431/99, Korea Atomic Energy Research Institute (1999).

[82] Wolsong 2, 3 \& 4 Final Safety Analysis Report, Korea Electric Power Corporation (1995).

[83] Atomic Energy of Canada Limited, "600 MWe CANDU-
PHW Wolsong-1 Nuclear Power Plant for the Korea Electric Company - Safety Report," Vol. 1-2(1980).

[84] H.C. Suk, J.S. Jun, J.Y. Jung, M.S. Cho, C.S. Lee, Y.B. Kim Y.D. Kim, S.D. Yi, and H.B. Seo, "Status of the Demonstration Irradiation of the CANDU New Fuel Bundle CANFLEX-NU in Korea," International CNS CANDU Fuel Conference, Muskoka, Canada, Sep. 22-24, 2003. 